\title{
QUEEN'S
UNIVERSITY
BELFAST
}

\section{Activity of innate antimicrobial peptides and ivacaftor against clinical cystic fibrosis respiratory pathogens}

\author{
Payne, J. E., Dubois, A. V., Ingram, R. J., Weldon, S., Taggart, C. C., Elborn, J. S., \& Tunney, M. M. (2017). \\ Activity of innate antimicrobial peptides and ivacaftor against clinical cystic fibrosis respiratory pathogens. \\ International Journal of Antimicrobial Agents, 50(3), 427-435. https://doi.org/10.1016/j.ijantimicag.2017.04.014
}

\section{Published in:}

International Journal of Antimicrobial Agents

\section{Document Version:}

Peer reviewed version

\section{Queen's University Belfast - Research Portal:}

Link to publication record in Queen's University Belfast Research Portal

\section{Publisher rights}

Copyright 2017 Elsevier.

This manuscript is distributed under a Creative Commons Attribution-NonCommercial-NoDerivs License

(https://creativecommons.org/licenses/by-nc-nd/4.0/), which permits distribution and reproduction for non-commercial purposes, provided the author and source are cited.

\section{General rights}

Copyright for the publications made accessible via the Queen's University Belfast Research Portal is retained by the author(s) and / or other copyright owners and it is a condition of accessing these publications that users recognise and abide by the legal requirements associated with these rights.

Take down policy

The Research Portal is Queen's institutional repository that provides access to Queen's research output. Every effort has been made to ensure that content in the Research Portal does not infringe any person's rights, or applicable UK laws. If you discover content in the Research Portal that you believe breaches copyright or violates any law, please contact openaccess@qub.ac.uk. 
1 Activity of innate antimicrobial peptides and ivacaftor against clinical cystic

2 fibrosis respiratory pathogens

3

4 Joanna E Payne, ${ }^{a, b}$ Alice V. Dubois, ${ }^{b}$ Rebecca J Ingram, ${ }^{b}$ Sinead Weldon, ${ }^{c}$ Clifford

5 C. Taggart, ${ }^{\mathrm{c}} \mathrm{J}$ Stuart Elborn, ${ }^{\mathrm{a}, \mathrm{b}}$ Michael M Tunney ${ }^{\mathrm{a}, \mathrm{d} \#}$

7 aHalo Research Group, Queen's University Belfast, Belfast, United Kingdom

$8{ }^{b}$ Centre for Experimental Medicine, School of Medicine, Dentistry \& Biomedical

9 Science, Queen's University Belfast, Belfast, United Kingdom

10 'Airway Innate Immunity Group (AIIR), School of Medicine, Centre for Experimental

11 Medicine, Dentistry \& Biomedical Science, Queen's University Belfast, Belfast,

12 United Kingdom

${ }^{d}$ School of Pharmacy, Queen's University Belfast, Belfast, United Kingdom

14 \#Corresponding author: Michael M. Tunney, School of Pharmacy, Queen's

15 University Belfast, 97 Lisburn Road, Belfast, BT9 7BL, United Kingdom 
Email addresses:

20 Joanna E Payne, jpayne05@qub.ac.uk

21 Alice Dubois, a.dubois@qub.ac.uk

22 Rebecca J Ingram, b.ingram@qub.ac.uk

23 Sinead Weldon, s.weldon@qub.ac.uk

24 Cliff Taggart, c.taggart@qub.ac.uk

25 J. Stuart Elborn, s.elborn@qub.ac.uk

26 Michael M. Tunney, m.tunney@qub.ac.uk

27

28 
There is a clear need for new antimicrobials to improve current treatment of chronic lung infection in people with cystic fibrosis (CF). This study determined the activity of antimicrobial peptides (AMPs) and ivacaftor, a novel CF transmembrane regulator potentiator for treatment of CF. Antimicrobial activity of AMPs (LL37, Human $\beta$ Defensins $[H \beta D] 1-4$ and SLPI) and ivacaftor against clinical respiratory isolates (Pseudomonas aeruginosa, Staphylococcus aureus, Streptococcus spp., Achromobacter spp. and Stenotrophomonas maltophilia) were determined using radial diffusion and time-kills assays, respectively. Synergy of LL37 and ivacaftor with tobramycin was determined by time-kill with in vivo activity of ivacaftor and tobramycin compared using a murine infection model. LL37 and HßD3 were the most active AMPs tested with MICs for genera ranging from 1.1-51.9 mg/L and 1-35.4 mg/L, respectively, with the exception of Achromobacter which was resistant. HßD1 and SLPI demonstrated no antimicrobial activity. LL37 demonstrated synergy with tobramycin against 4/5 S. aureus and 2/5 Streptococcus spp. isolates. Ivacaftor demonstrated bactericidal activity against Streptococcus spp. (mean $\log _{10}$ decrease $3.31 \mathrm{CFU} / \mathrm{ml}$ ), bacteriostatic activity against $S$. aureus (mean $\log _{10}$ change $0.13 \mathrm{CFU} / \mathrm{ml}$ ) but no activity against other genera. Moreover, ivacaftor demonstrated synergy with tobramycin with a mean $\log _{10}$ decrease of $5.72 \mathrm{CFU} / \mathrm{ml}$ and $5.53 \mathrm{CFU} / \mathrm{ml}$ at 24 hours

48 for S. aureus and Streptococcus spp., respectively. Ivacaftor demonstrated immunomodulatory but no antimicrobial activity in a $P$. aeruginosa in vivo murine infection model. Following further modulation to enhance activity, AMPs and ivacaftor

51 offer real potential as therapeutics to augment antibiotic therapy of respiratory infection 52 in CF. 
53 Key words: Ivacaftor, Cystic Fibrosis, antimicrobial, Pseudomonas aeruginosa, 54 innate antimicrobial peptides

55

56

57 


\section{Introduction}

Cystic fibrosis (CF) is a hereditary disease caused by mutations in the cystic fibrosis transmembrane conductance regulator (CFTR) gene. Respiratory failure caused by repeated cycles of infection and inflammation is the leading cause of morbidity and mortality in people with CF and is responsible for $80 \%$ of deaths [1]. Although Pseudomonas aeruginosa is the most frequently isolated CF respiratory pathogen [2], infection caused by other bacteria including Staphylococcus aureus, Burkholderia cepacia complex, Stenotrophomonas maltophilia, Achromobacter spp. and Streptococcus spp. [3,4] also occur. As a result, primarily due to increased use of antibiotics, bacteria causing respiratory infection are becoming progressively more resistant to conventional antibiotics with up to $45 \%$ of CF patients colonised with multidrug resistant pathogens [5-7]. Furthermore, when chronic infection is established, pathogens such as $P$. aeruginosa grow within polymicrobial biofilms in the CF lung and exhibit increased resistance to antibiotics $[8,9]$. Tobramycin is the most frequently prescribed inhaled antibiotic for CF patients with chronic $P$. aeruginosa infection [2], with ciprofloxacin frequently prescribed as an oral antibiotic [10]. However, in a recent study of CF $P$. aeruginosa isolates in Northern Europe, $60 \%$ were multidrug resistant with $28 \%$ and $56 \%$ resistant to tobramycin and ciprofloxacin, respectively [11].Therefore, there is a clear need for novel antimicrobial agents or combinations of antimicrobials to treat respiratory infection in CF patients.

Antimicrobial peptides (AMPs) form part of the non-specific innate immune response and have been shown to have antibacterial activity [12]. Some of the most well characterised AMPs include the human cathelicidin LL37, Human $\beta$-defensins 1-4 (HßD1-4) and secretory leukocyte protease inhibitor (SLPI) which are all produced by the lung epithelium [13-15]. The antibacterial properties of these peptides have been 
83 previously demonstrated [16-19], but only LL37 has been specifically tested against 84 clinical CF respiratory isolates.

85 Ivacaftor is a first-in-class CFTR potentiator that potentiates defective CFTR at the 86 apical membrane of lung epithelial cells, thus increasing the probability of successful 87 chloride transport across the membrane [20]. Treatment results in sweat chloride correction, decreased exacerbation frequency and an improvement in lung function and quality of life [21]. Furthermore, Reznikov et al. reported that ivacaftor demonstrated some antimicrobial activity against laboratory and non-CF clinical

91 methicillin susceptible and resistant S. aureus (MSSA and MRSA) and Streptococcus

92 pneumoniae isolates [22] and suggested that this may be due to the presence of a 93 quinolone ring.

94 The aim of this study was to determine the antimicrobial activity of a number of AMPs 95 and ivacaftor against clinical CF respiratory isolates from a range of genera. 96 Furthermore, we investigated if there was synergy between LL37 or ivacaftor and 97 tobramycin. Finally, a murine infection model was used to compare the in vivo antimicrobial and immunomodulatory activity of ivacaftor and tobramycin. 


\section{Materials and Methods}

101

102

103

104

105

106

107

108

109

110

111

112

113

114

\subsection{Bacterial isolates}

Eighteen clinical bacterial isolates $[P$. aeruginosa, $n=4 ; S$. aureus $n=4(M R S A, n=3$; MSSA n=1); Streptococcus spp., $n=4$; Achromobacter spp., $n=3$ and S. maltophilia, $n=3$ ] were used for susceptibility testing. The isolates were cultured from sputum samples or bronchoalveolar lavage fluid collected from CF patients attending CF clinics in Belfast and the University of North Carolina at Chapel Hill. Samples were cultured on non-selective agar plates and individual colonies sub-cultured to obtain pure bacterial culture. Bacterial isolates were identified using 16S rRNA sequencing as described previously [23]. Bacterial isolates were stored at $-80^{\circ} \mathrm{C}$. P. aeruginosa ATCC 27853, S. aureus ATCC 29213 and Streptococcus anginosus NCTC 10713 were included as quality control and reference strains. In biofilm assays, S. epidermidis ATCC 35984 was used as a strong biofilm former (positive control) and a laboratory S. capitis isolate was used as a weak biofilm former (negative control). P. aeruginosa strain PAO1 was used for in vivo experiments.

\subsection{Antimicrobials and reagents}

Etest ${ }^{\circledR}$ strips were purchased from bioMerieux (North Carolina, USA). Ivacaftor was purchased from Selleckchem (Houston, USA), synthetic LL37 and synthetic HBD1-4 from Innovagen (Lund, Sweden) and recombinant human SLPI from R\&D Systems (Minneapolis, USA); All AMPs were active. Tobramycin was obtained from Hospira (Warwickshire, UK). Ciprofloxacin ( $\geq 98 \%$ HPLC grade), monobasic and dibasic sodium phosphate, agarose (Type 1, low EEO), methanol ( $\geq 99.9 \%$ HPLC grade), crystal violet (for biofilm staining), Dulbeco's phosphate buffered saline (PBS) (endotoxin tested) and trypan blue were all purchased from Sigma-Aldrich (Gillingham, 
125 UK). Mueller Hinton agar (MHA), Mueller Hinton broth (MHB), Cetrimide agar, Anaerobe Basal agar (ABA) and Brain Heart infusion (BHI) broth were all purchased from Oxoid Ltd (Basingstoke, UK). Sterile, defibrinated horse blood was purchased from TCS Biosciences (Buckingham, UK). Xylazine (Xylacare 2\% w/v) and Ketamine (Narketan 10, 100g/L) were obtained from Animalcare (York, UK) and Ventoquinol (Buckinghamshire, UK), respectively. IL-6 and KC enzyme-linked immunosorbent assay (ELISA) kits were purchased from eBioscience (Hatfield, UK) and R\&D Systems (Minneapolis, USA), respectively.

\subsection{MIC testing}

The MICs of antibiotics (Supplementary Table 1) routinely used in the treatment of CF lung infection were determined by Etest ${ }^{\circledR}$ according to the manufacturer's instructions. The MICs of AMPs (LL37, HßD1-4 and SLPI) were determined using a radial diffusion assay (RDA) as previously described [24]. BHI supplemented agar was used with Streptococcus spp., S. maltophilia and Achromobacter spp. with MHA used for $P$. aeruginosa and S. aureus. Peptides were tested at concentrations of 200, 150, 100 and $50 \mathrm{mg} / \mathrm{L}$.

\subsection{LL37 and tobramycin synergy}

A modified time-kill assay was used to determine if there was synergy between LL37 and tobramycin against selected isolates ( $P$. aeruginosa [n=5]; S. aureus [n=5] and Streptococcus spp. [n=5]). Overnight cultures were washed with $10 \mathrm{mM}$ sodium phosphate and adjusted to approximately $1 \times 10^{5} \mathrm{CFU} / \mathrm{ml}$. In a 96 -well plate, the bacterial suspension was incubated with LL37 (64-1 mg/L) alone or in combination with tobramycin (0.5 MIC for each isolate) for 3 hours at $37^{\circ} \mathrm{C}$ under aerobic or microaerophilic conditions. Killing activity was assessed by enumerating on MHA or 
ABA following serial dilution $\left(10^{-1}\right.$ to $\left.10^{-3}\right)$ in sterile saline. The MBC of LL37 was determined as the lowest concentration at which there was no growth on the plate. Synergy was defined as a $\geq 2 \log _{10}$ decrease in total viable count (TVC) compared to the starting inoculum and as $a \geq 2 \log _{10}$ decrease in TVC by the combination compared to the most active single agent [25]. Results are expressed as mean CFU/ml $\pm S D$.

\subsection{Time-kill studies}

155

All time-kill experiments were performed according to CLSI standards [25]. Initial timekill studies were performed using a range of ivacaftor concentrations $(32,16,8,4$ and $1 \mathrm{mg} / \mathrm{L})$ against selected isolates ( $P$. aeruginosa [n=5]; $S$. aureus $[\mathrm{n}=5]$ and Streptococcus spp. [n=5]); the highest concentration of ivacaftor tested (32 mg/L) was that previously used by Reznikov et al. [22]. Ivacaftor was dissolved in DMSO and time-kills were also performed using DMSO (0.32\%) as a reagent control. Subsequently, time-kill assays were performed with these isolates to compare the activity of ivacaftor (32 mg/L) with ciprofloxacin ( $5 \mathrm{mg} / \mathrm{L}$; concentration above MIC for the majority of isolates), a comparator fluoroquinolone. Time-kill assays were performed in $\mathrm{MHB}$ for $P$. aeruginosa and $S$. aureus isolates and $\mathrm{BHI}$ broth for Streptococcus spp.

For synergy studies, ivacaftor was used at a concentration of $32 \mathrm{mg} / \mathrm{L}$ in combination with tobramycin at $0.5 \mathrm{MIC}$. Tobramycin was chosen for synergy studies as it is the most frequently prescribed inhaled antibiotic in CF and is also frequently prescribed for treatment of acute infective exacerbations [2]. A no drug control was used in each assay.

Bacterial cultures and antibiotics were incubated at $37^{\circ} \mathrm{C}$ under aerobic or microaerophilic (5\% $\mathrm{CO}_{2}$ for Streptococci) conditions. Killing activity was assessed at 

by enumerating on MHA or ABA agar. Bactericidal activity was defined as a $\geq 3 \log _{10}$ reduction in colony forming units (CFU/ml) in the original inoculum [25]. Synergy was defined as described above [25] with results for time-kill assays expressed as mean

$177 \mathrm{CFU} / \mathrm{ml} \pm \mathrm{SD}$.

\subsection{Biofilm Studies}

The effect of ivacaftor on bacterial adherence and biofilm formation by all isolates (clinical isolates $n=18$; reference strains, $n=3$ ) was determined using a previously described method that quantifies the adherence of bacteria to microtitre plates (ThermoFisher Scientific, Waltham, USA) [26]. An overnight culture of bacteria was adjusted to $1 \times 10^{6} \mathrm{CFU} / \mathrm{ml}$ with $200 \mu$ lded to each well. Ivacaftor (32 $\left.\mathrm{mg} / \mathrm{L}\right)$, ciprofloxacin $(5 \mathrm{mg} / \mathrm{L})$ or DMSO $(0.32 \%)$ were added to the wells and the plates were incubated for 24 hours at $37^{\circ} \mathrm{C}$. The contents of the wells were aspirated, washed three times with $200 \mu$ l sterile PBS and adherent bacteria stained using crystal violet. Bacterial adherence was quantified by measurement of OD570 (FLUOstar Omega microplate reader) and compared with an untreated control. Limits for non, weak, moderate and strong biofilm formation were defined as previously described [26].

\subsection{In vivo activity using a mouse model of intraperitoneal infection}

The in vivo activity of ivacaftor was determined using a systemic sepsis model of infection in mice. Age and sex matched B6 mice (B6N-Tyrc-Brd/BrdCrCrl [Charles River]) mice ( $n=5$ per group; 4 male, 1 female) were inoculated intraperitoneally (IP) with 100 $\mu$ of $P$. aeruginosa (PAO1) $\left(6 \times 10^{8} \mathrm{CFU} / \mathrm{ml}\right)$. PAO1 was used as our group and others have shown that it reproducibly produces intraperitoneal infection in mice [27]. Ivacaftor (60 $\mu \mathrm{g} /$ mouse), negative control (endotoxin free PBS) or tobramycin (140 
$\mu \mathrm{g} /$ mouse), were administered IP immediately following infection. The dose of ivacaftor used in this model was calculated based on a single adult dose (150mg) adjusted for mouse weight $(20 \mathrm{~g})$ and the assumption that an adult with CF weighs 50 $\mathrm{kg}$. The dose of tobramycin used was calculated based on the intravenous once daily dose paediatric regimen of $7 \mathrm{mg} / \mathrm{kg}$ adjusted for mouse weight $(20 \mathrm{~g})$. The bacterial load inoculated was chosen to ensure systemic infection was achieved with mice sacrificed after 4 hours to prevent significant deterioration in health. A peritoneal lavage was performed with $5 \mathrm{ml}$ of ice-cold sterile PBS, with collected samples stored on ice. Total viable count of PAO1 from the lavage was determined by enumerating on cetrimide agar, a $P$. aeruginosa selective agar. Total cell count and cell viability were determined following staining with trypan blue using the Countess ${ }^{\mathrm{TM}}$ Automated supernatant used to determine IL-6 and KC (chemokine CXCL1, a functional homologue of human IL-8) levels by ELISA. Housing and experimentation was carried out in accordance with the Animal (Scientific Procedures) Act 1986 and current guidelines approved by the Queen's University Ethical Review Committee.

\subsection{Statistical analysis}

One-way ANOVA and Bonferroni's Multiple Comparison Tests were used to determine statistical significance in the biofilm assays and in the in vivo experiments. All analysis was performed using GraphPad software with a P-value of $<0.05$ considered statistically significant. 


\section{Results}

220

221

222

223

224

225

226

227

228

229

230

231

232

233

234

235

236

237

238

239

240

241

242

\subsection{MIC testing}

The MICs of antibiotics routinely used in the treatment of CF lung infection were determined for all isolates (Supplementary Table 1) with differences in susceptibility apparent both within and between genera. The majority of $P$. aeruginosa $(4 / 5 ; 80 \%)$ and S. aureus $(4 / 5 ; 80 \%)$ isolates were susceptible to tobramycin; however, high tobramycin MICs were demonstrated for Streptococcus (3/5; 60\%), Achromobacter $(3 / 3 ; 100 \%)$ and S. maltophilia $(4 / 5 ; 80 \%)$ isolates. With the exception of Streptococci, where all isolates displayed intermediate resistance, based on the breakpoint for $S$. pneumoniae, resistance and susceptibility to ciprofloxacin was apparent within each genera.

The MIC for each antimicrobial peptide against clinical isolates from each genus is summarised in Table 1 with the MICs of type strains presented for comparison. The MICs for individual isolates are also presented in Supplementary Table 2. Overall, LL37 and HßD3 were the most active peptides tested with MICs for genera ranging from 1.1-51.9 $\mathrm{mg} / \mathrm{L}$ and $1-35.4 \mathrm{mg} / \mathrm{L}$, respectively, with the exception of Achromobacter which was resistant. In contrast, HßD1 and SLPI demonstrated no activity against any isolates at the concentrations tested. Peptide MICs for type strains were within the range of those for clinical isolates, with the exception of S. anginosus

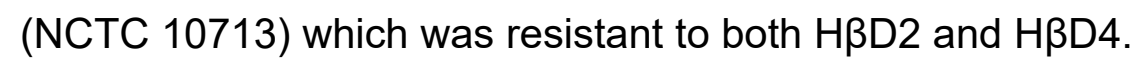

\subsection{Synergy between LL37 and tobramycin}

When combined with tobramycin, LL37 demonstrated no synergistic activity against P. aeruginosa (Table 2). In contrast, LL37 demonstrated synergistic activity in combination with tobramycin against 4/5 S. aureus and 2/5 Streptococcus spp. 
243 isolates (Table 2). Change in CFU/ml for individual isolates is presented in 244 supplementary Table 3.

\subsection{Bactericidal activity of ivacaftor}

246 When tested alone, ivacaftor demonstrated no antimicrobial activity against $P$. 247 aeruginosa at any concentration tested (Fig. 1A). In contrast, at the highest concentration tested, $32 \mathrm{mg} / \mathrm{L}$, bacteriostatic activity was apparent against all $\mathrm{S}$. aureus isolates tested (Fig. 1B). Similarly, bacteriostatic ( $\mathrm{n}=3$ isolates) and bactericidal ( $n=2$ isolates) activity was apparent against Streptococcus spp. isolates (Fig. 1C) at this concentration with no effect apparent against any genera at lower concentrations. DMSO $(0.32 \%)$ had no effect on bacterial growth in any assay. Individual time-kill curves are presented for $P$. aeruginosa (Supplementary Fig. 1), S. aureus (Supplementary Fig. 2) and Streptococcus spp. isolates (Supplementary Fig. 3.).

The change in CFU/mL in the presence of ivacaftor, ciprofloxacin or untreated control at 24 hours for isolates within each genus is summarised in Table 3. Ciprofloxacin demonstrated bactericidal activity against $16 / 21$ isolates tested with no growth detected at 24 hours. In contrast, ivacaftor only demonstrated bactericidal activity against 2/21 isolates tested, both of which were clinical Streptococcus spp.

There was no synergy between ivacaftor and tobramycin against $P$. aeruginosa (Fig.

2A, Table

4). In contrast

synergy

was apparent for $4 / 5$

S. aureus and $4 / 5$ effect on growth of the isolates. 
267 Biofilm formation was classified as non-adherent, weak, moderate or strong; 2/5 $P$. aeruginosa, 1/5 Streptococcus and 1/3 Achromobacter species were non-adherent and were excluded from further analysis. Of the remaining 17 isolates, 10, demonstrated weak adherence, 4 demonstrated moderate adherence and 3 were strong biofilm formers. Treatment with ivacaftor resulted in a significant decrease $(P$ $<0.001$ ) in biofilm formation for 1/3 P. aeruginosa and 2/4 Streptococcus spp. biofilm forming isolates. However, ivacaftor had no effect on biofilm formation by the remaining isolates tested ( $n=14$; Fig. 3). Similarly, ciprofloxacin did not decrease biofilm formation by $S$. aureus isolates $(n=5)$. However, ciprofloxacin caused a significant decrease $(P<0.001)$ in biofilm formation for $7 / 12$ isolates $(P$. aeruginosa, n=2/3, Streptococcus spp., $n=1 / 4$, Achromobacter spp., $n=1 / 2$; Stenotrophomonas spp., $n=3 / 3)$ across the other genera tested (Fig. 3). DMSO (0.32\%) had no effect on bacterial adherence in any assay.

There was no significant difference between the control group (PBS) and any of the treatment groups in the total number of cells recovered from the IP lavage or cell viability (Fig. 4A \& 4B). However, compared with control, treatment with tobramycin caused a significant decrease in the TVC of $P$. aeruginosa recovered from the peritoneal lavage (Fig. 4C). In contrast, there was no significant difference when the mice were treated with ivacaftor. Both treatments caused a significant reduction in IL6 levels (Fig. 4D); however, KC was only significantly reduced in the group treated with tobramycin (Fig. 4E). 


\section{Discussion}

291

292

293

294

295

296

297

298

299

300

301

302

303

304

305

306

307

As bacteria causing pulmonary infection in CF become progressively more resistant to conventional antibiotics, interest in the use of AMPs as antimicrobials for treatment has increased considerably. In the present study, we have shown that LL37 and HßD3 possess antibacterial properties against CF respiratory pathogens such as $P$. aeruginosa, MRSA and S. maltophilia. Moreover, both of these AMPs demonstrated antibacterial activity against clinical isolates which were resistant to antibiotics routinely used in the treatment of CF pulmonary infection such as ciprofloxacin, tobramycin and meropenem. SLPI had no activity against any genera tested in the present study. These results contrast to those previously published which reported activity of SLPI against both $P$. aeruginosa and S. aureus [16]. However, in the study by Wiedow et al. [16], antibacterial activity of SLPI was assessed using a time-kill assay with a single dermatological $P$. aeruginosa and $S$. aureus isolate. No data were provided with respect to the antibiotic susceptibility of these two isolates. It is likely that the isolates used in the present study demonstrated greater inherent antimicrobial resistance due to prolonged and repeated exposure to antibiotics, which may account for the lack of concordance between studies.

If used clinically, it is likely that AMPs would need to be administered by inhalation in combination with an antibiotic to directly target the site of infection. Therefore, we determined the activity of the most potent AMP, LL37, in combination with tobramycin, the most frequently prescribed inhaled antibiotic for treatment of $P$. aeruginosa pulmonary infection in CF [2]. This combination demonstrated greater antimicrobial activity than either agent alone against both clinical S. aureus and Streptococcus spp. isolates. However, no synergistic activity was apparent against $P$. aeruginosa. In 
contrast to our findings, it has been previously reported that LL37 and tobramycin in combination demonstrate enhanced killing of $P$. aeruginosa biofilms [28]. However, the concentration of both LL37 (640 mg/L) and tobramycin $(160-2560 \mathrm{mg} / \mathrm{L})$ used in this biofilm killing study were considerably higher than those used in the present study which ranged from 1-64 mg/L and 0.25-3 mg/L for LL37 and tobramycin, respectively. Synergy may also have been apparent in our study if we had used both LL37 and tobramycin at higher concentrations. Despite the excellent antimicrobial activity demonstrated by LL37 and HßD-3, we were unable to perform further work such as biofilm assays due to the high cost of these AMPs.

As previous studies have reported that ivacaftor, a first-in-class CFTR potentiator, has some antimicrobial activity against non-CF clinical isolates such as $S$. aureus, we determined its antimicrobial activity against clinical CF respiratory isolates from a range of genera. Using quantitative culture time-kill assays, we demonstrated activity, but no activity against $P$. aeruginosa, S. maltophilia and Achromobacter species. This result is consistent with the findings of Reznikov et al. who reported that ivacaftor had some antimicrobial activity against Streptococcus spp. and S. aureus, but was not active against $P$. aeruginosa [22]. Similar to Reznikov et al., who reported enhanced antimicrobial activity when ivacaftor was used in combination with vancomycin or ciprofloxacin, we also found a synergistic effect against S. aureus and Streptococcus spp. when ivacaftor was combined with tobramycin.

Reznikov et al. suggested that the antimicrobial activity of ivacaftor may be due to the presence of a quinolone ring in its structure, similar to that of fluoroquinolone antibiotics such as ciprofloxacin [22]. Quinolones are broad spectrum antibiotics and 
are typically more active against Gram negative bacteria. In the present study, ciprofloxacin demonstrated bactericidal activity against both Gram-positive bacteria (S. aureus and Streptococcus spp.) and Gram-negative bacteria (P. aeruginosa, S. maltophilia and Achromobacter spp.), consistent with broad-spectrum activity expected from a conventional quinolone antibiotic. In contrast, ivacaftor had no activity against any of the Gram negative isolates tested, suggesting that its antimicrobial effect may not be directly related to the quinolone ring in the structure. Alternatively, lack of activity against Gram negative bacteria could be due to a number of other potential mechanisms such as inability to cross the outer membrane and enzymatic inactivation.

In addition to clinical outcomes, the effect of ivacaftor treatment on the CF lung microbiota was also determined in the GOAL study, a longitudinal cohort study of 151 CF patients before and up to 6 months after ivacaftor initiation. A significant reduction in the number of patients from whom $P$. aeruginosa was cultured from sputum samples either through a decrease in $P$. aeruginosa culture positivity over 6 months [29] or change from $P$. aeruginosa culture positive to negative over the course of a year [30] was reported. In contrast, there was no significant change in sputum culture positivity for MRSA, MSSA, Stenotrophomonas spp. or Achromobacter spp. [29,30]. Similarly, in a small study of three paediatric CF patients, a reduction in the relative abundance of Streptococcus spp. was reported following treatment with ivacaftor. The results of our study suggest that these changes in Streptococcus relative abundance could be due to the antimicrobial activity of ivacaftor on this genus; however, the increased abundance of other genera detected could also account for this change [31]. In contrast, our results, which clearly show that ivacaftor has no direct antimicrobial activity against $P$. aeruginosa, growing planktonically or in biofilm, suggest that the 
change in $P$. aeruginosa culture positivity reported in the GOAL study is more likely attributed to increased mucociliary clearance resulting in increased clearance of biofilm from the airways. The concentration of ivacaftor achieved in sputum following oral administration has not been reported to date; however, it is likely to be significantly lower than the reported serum levels of $\sim 1.4 \mathrm{mg} / \mathrm{L}$ [32]. Therefore, the concentration of ivacaftor (32 mg/L) which demonstrated antimicrobial activity in both our study and that of Reznikov et al. [22] is likely to be considerably higher than that achievable in sputum following oral administration. This further supports the hypothesis that changes in pathogen culture positivity reported post-ivacaftor treatment are not as a result of a direct antimicrobial effect.

Given that pulmonary infection in the CF airways involves bacterial growth in biofilms $[8,9]$, we also determined the effect of ivacaftor on biofilm formation. The effect of ciprofloxacin on biofilm formation was also determined to enable comparison between ivacaftor and a fluoroquinolone antibiotic with a related chemical structure. In general, ivacaftor had limited effect on biofilm formation. However, as the majority of isolates demonstrated weak adherence, any change attributable to the use of ivacaftor was difficult to detect. The decrease in adherence for 2/5 Streptococcus spp. isolates is likely due to the bactericidal activity of ivacaftor against these isolates. In contrast, ivacaftor had no antimicrobial activity against $P$. aeruginosa and thus the decrease in biofilm formation with one $P$. aeruginosa isolate is indicative of inhibition of adherence. Ciprofloxacin demonstrated bactericidal activity against the majority of isolates tested; therefore, inhibition of biofilm formation could be as a result of either a direct effect on bacterial adherence or bacterial cell death before adherence could occur. 
386 It has been previously reported that ivacaftor has some immunomodulatory activity 387 with Bratcher et al. (2015) demonstrating a decrease towards normalisation of blood leukocyte activation following ivacaftor treatment [33]. To establish whether ivacaftor exhibited any antimicrobial or immunomodulatory activity in vivo, an acute systemic mouse infection model was used; mice were administered ivacaftor or tobramycin at doses approximately reflecting those used in humans. Ivacaftor demonstrated no antimicrobial activity in this model; however, there was some indication of modulation of the innate immune response, based on the reduced production of cytokines and chemokines. The immunomodulatory effect of fluoroquinolones has been widely documented [34]; furthermore, in a mouse injury model, treatment with ciprofloxacin demonstrated here.

There are a number of limitations to this study. Firstly, the AMPs used were expensive restricting the volumes that could be used for testing; therefore, we could not determine MIC by the preferred microbroth dilution method or bactericidal activity using time-kill assays. This also limited the number and range of isolates which could be tested. Physiological conditions may also be important when evaluating AMPs as potential novel antimicrobial therapies. It has been suggested that higher salt concentration in CF airway surface liquid could reduce the antimicrobial activity of AMPs [36] by affecting the ionic interaction between the AMPs and bacterial membranes. Moreover, It has also been demonstrated that in CF sputum, LL37 is inactivated by binding to DNA, F-actin and cell debris bundles [37]. In contrast, it has 
411 also been demonstrated that the presence of carbonate, which is found in many 412 microenvironments of the body including the respiratory tract, can greatly enhance 413 bacterial susceptibility to AMPs under physiological ionic conditions [38]. Therefore, 414 further work testing AMP activity under conditions more reflective of the environment 415 present in the CF airways would be required if these compounds were being 416 considered as potential therapeutics to treat CF pulmonary infection. Furthermore, 417 tobramycin was the only antibiotic used in synergy studies with LL37 and ivacaftor. 418 Given the wide range of antibiotics used in the prophylaxis and treatment of CF 419 pulmonary infection, future work to determine synergy between an extended range of 420 antibiotics and LL37/ivacaftor could be of potential clinical benefit. 


\section{5. Conclusion}

424 In summary, we have shown that the AMPs, LL37 and HBD3, demonstrate 425 antimicrobial activity against CF pathogens from a range of genera with LL37 also 426 demonstrating synergistic activity, in combination with tobramycin, against $S$. aureus 427 and Streptococcus spp. isolates. Similarly, ivacaftor demonstrated bactericidal activity 428 against $S$. aureus and Streptococcus spp. isolates but no activity against Gram429 negative bacteria. There is a low propensity for the development of resistance to AMPs 430 due to the interaction of the peptides with the cytoplasmic membrane of bacteria and 431 their bactericidal nature [12]. Therefore, AMPs could potentially be developed as novel 432 therapeutic options but further work is required to enhance their activity. 


\section{Funding}

438 This work was supported by a Department for Employment and Learning PhD studentship, an EU FP7 Grant (CFMATTERS; grant agreement number 603038), a HSC Research and Development Grant from the Public Health Agency Northern 441 Ireland and through a US-Ireland Project Partnership Grant.

\section{References}

[1] O'Sullivan BP, Freedman SD. Cystic fibrosis. Lancet 2009;373:1891-904.

[2] Carr S, Cosgriff R, Rajabzadeh-Heshejin V. UK Cystic Fibrosis Registry 2015 Annual Data Report. 2016.

[3] Boutin S, Graeber SY, Weitnauer M, Panitz J, Stahl M, Clausznitzer D, et al. Comparison of microbiomes from different niches of upper and lower airways in children and adolescents with cystic fibrosis. PLoS One 2015;10:e0116029.

[4] Tunney MM, Klem ER, Fodor AA, Gilpin DF, Moriarty TF, McGrath SJ, et al. Use of culture and molecular analysis to determine the effect of antibiotic treatment on microbial community diversity and abundance during exacerbation in patients with cystic fibrosis. Thorax 2011;66:579-84.

[5] Emerson J, McNamara S, Buccat AM, Worrell K, Burns JL. Changes in cystic fibrosis sputum microbiology in the United States between 1995 and 2008. Pediatr Pulmonol 2010;45:363-70.

[6] Merlo CA, Boyle MP, Diener-West M, Marshall BC, Goss CH, Lechtzin N. Incidence and risk factors for multiple antibiotic-resistant Pseudomonas aeruginosa in cystic fibrosis. Chest 2007;132:562-8. 
460

461

462

463

464

465

466

467

468

469

470

471

472

473

474

475

476

477

478

479

480

481

482

[7] Sherrard LJ, Tunney MM, Elborn JS. Antimicrobial resistance in the respiratory microbiota of people with cystic fibrosis. Lancet 2014;384:703-13.

[8] Bjarnsholt T, Jensen PØ, Fiandaca MJ, Pedersen J, Hansen CR, Andersen $\mathrm{CB}$, et al. Pseudomonas aeruginosa biofilms in the respiratory tract of cystic fibrosis patients. Pediatr Pulmonol 2009;44:547-58.

[9] Singh PK, Schaefer AL, Parsek MR, Moninger TO, Welsh MJ, Greenberg EP. Quorum-sensing signals indicate that cystic fibrosis lungs are infected with bacterial biofilms. Nature 2000;407:762-4.

[10] Remmington T, Jahnke N, Harkensee C. Oral anti-pseudomonal antibiotics for cystic fibrosis. Cochrane Database Syst Rev 2016.

[11] Mustafa M-H, Chalhoub H, Denis O, Deplano A, Vergison A, RodriguezVillalobos $\mathrm{H}$, et al. Antimicrobial susceptibility of Pseudomonas aeruginosa isolated from cystic fibrosis patients through Northern Europe. Antimicrob Agents Chemother 2016:AAC.01046-16.

[12] Marr AK, Gooderham WJ, Hancock RE. Antibacterial peptides for therapeutic use: obstacles and realistic outlook. Curr Opin Pharmacol 2006;6:468-72.

[13] Liu Q, Liu J, Roschmann KIL, van Egmond D, Golebski K, Fokkens WJ, et al. Histone deacetylase inhibitors up-regulate LL-37 expression independent of toll-like receptor mediated signalling in airway epithelial cells. J Inflamm (Lond) 2013;10:15.

[14] Scott A, Weldon S, Taggart CC. SLPI and elafin: multifunctional antiproteases of the WFDC family. Biochem Soc Trans 2011;39:1437-40.

[15] Duits LA, Ravensbergen B, Rademaker M, Hiemstra PS, Nibbering PH. 
Expression of beta-defensin 1 and 2 mRNA by human monocytes, macrophages and dendritic cells. Immunology 2002;106:517-25.

[16] Wiedow O, Harder J, Bartels J, Streit V, Christophers E. Antileukoprotease in human skin: an antibiotic peptide constitutively produced by keratinocytes. Biochem Biophys Res Commun 1998;248:904-9.

[17] García JR, Krause A, Schulz S, Rodríguez-Jiménez FJ, Klüver E, Adermann $\mathrm{K}$, et al. Human beta-defensin 4 : a novel inducible peptide with a specific saltsensitive spectrum of antimicrobial activity. FASEB J 2001;15:1819-21.

[18] Midorikawa K, Ouhara K, Komatsuzawa H, Kawai T, Yamada S, Fujiwara T, et al. Staphylococcus aureus Susceptibility to Innate Antimicrobial Peptides, Defensins and CAP18, Expressed by Human Keratinocytes. Infect Immun 2003;71:3730-9.

[19] Saiman L, Tabibi S, Starner TD, San Gabriel P, Winokur PL, Jia HP, et al. Cathelicidin peptides inhibit multiply antibiotic-resistant pathogens from patients with cystic fibrosis. Antimicrob Agents Chemother 2001;45:2838-44.

[20] Van Goor F, Hadida S, Grootenhuis PDJ, Burton B, Cao D, Neuberger T, et al. Rescue of CF airway epithelial cell function in vitro by a CFTR potentiator, VX770. Proc Natl Acad Sci U S A 2009;106:18825-30.

[21] Ramsey BW, Davies J, McElvaney NG, Tullis E, Bell SC, Dřevínek P, et al. A CFTR potentiator in patients with cystic fibrosis and the G551D mutation. $\mathrm{N}$ Engl J Med 2011;365:1663-72.

[22] Reznikov LR, Abou Alaiwa MH, Dohrn CL, Gansemer ND, Diekema DJ, Stoltz DA, et al. Antibacterial properties of the CFTR potentiator ivacaftor. J Cyst 
Fibros 2014;13:515-9.

507

508

509

510

511

512

513

514

515

516

517

518

519

520

521

522

523

524

525

526

527

[23] Tunney MM, Field TR, Moriarty TF, Patrick S, Doering G, Muhlebach MS, et al. Detection of Anaerobic Bacteria in High Numbers in Sputum from Patients with Cystic Fibrosis. Am J Respir Crit Care Med 2008;177:995-1001.

[24] Steinberg DA, Lehrer RI. Designer assays for antimicrobial peptides. Disputing the "one-size-fits-all" theory. Methods Mol Biol 1997;78:169-86.

[25] CLSI M26-A. Methods for determining bactericidal activity of antimicrobial agents; approved guideline. CLSI document M26-A. Pennsylvania, USA. Clin Lab Stand Inst 1999.

[26] Stepanović S, Vuković D, Dakić I, Savić B, Švabić-Vlahović M. A modified microtiter-plate test for quantification of staphylococcal biofilm formation. $\mathrm{J}$ Microbiol Methods 2000;40:175-9.

[27] Bucki R, Niemirowicz K, Wnorowska U, Byfield FJ, Piktel E, Wątek M, et al. Bactericidal Activity of Ceragenin CSA-13 in Cell Culture and in an Animal Model of Peritoneal Infection. Antimicrob Agents Chemother 2015;59:6274-82.

[28] Dosler S, Karaaslan E. Inhibition and destruction of Pseudomonas aeruginosa biofilms by antibiotics and antimicrobial peptides. Peptides 2014;62:32-7.

[29] Rowe SM, Heltshe SL, Gonska T, Donaldson SH, Borowitz D, Gelfond D, et al. Clinical mechanism of the cystic fibrosis transmembrane conductance regulator potentiator ivacaftor in G551D-mediated cystic fibrosis. Am J Respir Crit Care Med 2014;190:175-84.

[30] Heltshe SL, Mayer-Hamblett N, Burns JL, Khan U, Baines A, Ramsey BW, et al. Pseudomonas aeruginosa in cystic fibrosis patients with G551D-CFTR 
treated with ivacaftor. Clin Infect Dis 2014.

530

531

532

533

534

535

536

537

538

539

540

541

542

543

544

545

546

547

548

549

550

551

[31] Bernarde C, Keravec M, Mounier J, Gouriou S, Rault G, Férec C, et al. Impact of the CFTR-Potentiator Ivacaftor on Airway Microbiota in Cystic Fibrosis Patients Carrying A G551D Mutation. PLoS One 2015;10:e0124124.

[32] Raggio M, Witzmann K, Durmowicz A. Approval Package for: Application Number 203188Orig1s000. Cent Drug Eval Res 2012.

[33] Bratcher PE, Rowe SM, Reeves G, Roberts T, Szul T, Harris WT, et al. Alterations in blood leukocytes of G551D-bearing cystic fibrosis patients undergoing treatment with ivacaftor. J Cyst Fibros 2015;15:67-73.

[34] Dalhoff A. Immunomodulatory Activities of Fluoroquinolones. Infection 2005;33:55-70.

[35] Fukumoto R, Cary LH, Gorbunov N V, Lombardini ED, Elliott TB, Kiang JG. Ciprofloxacin modulates cytokine/chemokine profile in serum, improves bone marrow repopulation, and limits apoptosis and autophagy in ileum after whole body ionizing irradiation combined with skin-wound trauma. PLoS One 2013;8:e58389.

[36] Goldman MJ, Anderson GM, Stolzenberg ED, Kari UP, Zasloff M, Wilson JM. Human $\beta$-Defensin-1 Is a Salt-Sensitive Antibiotic in Lung That Is Inactivated in Cystic Fibrosis. Cell 1997;88:553-60.

[37] Bucki R, Byfield FJ, Janmey PA. Release of the antimicrobial peptide LL-37 from DNA/F-actin bundles in cystic fibrosis sputum. Eur Respir J 2007;29.

[38] Dorschner RA, Lopez-Garcia B, Peschel A, Kraus D, Morikawa K, Nizet V, et al. The mammalian ionic environment dictates microbial susceptibility to 
antimicrobial defense peptides. FASEB J 2006;20:35-42.

553 [39] EUCAST. The European Committee on Antimicrobial Susceptibility Testing. Breakpoint tables for interpretation of MICs and zone diameters. Version 6.0. 2016. 
Table 1

Antimicrobial activity (MIC range) of antimicrobial peptides against CF respiratory isolates and reference strains $P$. aeruginosa (ATCC 27853), S. aureus (ATCC 29213) and S. anginosus (NCTC 10713).

MIC Range (mg/L)

\begin{tabular}{|c|c|c|c|c|c|c|}
\hline Genus & LL37 & $\mathrm{H} \beta \mathrm{D} 1$ & $\mathrm{H} \beta \mathrm{D} 2$ & $\mathrm{H} \beta \mathrm{D} 3$ & $\mathrm{H} \beta \mathrm{D} 4$ & SLPI \\
\hline Pseudomonas $(n=4)$ & $3.9-22.8$ & $>200$ & $43.4->200$ & 6.4-17.6 & $39.1-49.3$ & $>200$ \\
\hline ATCC 27853 & 3.2 & $>200$ & 28.6 & 13.9 & 17.8 & $>200$ \\
\hline Staphylococcus $(n=4)$ & 15.7-29.9 & $>200$ & $>200$ & $8.9-9.6$ & $>200$ & $>200$ \\
\hline ATCC 29213 & 21.5 & $>200$ & $>200$ & 12.7 & $>200$ & $>200$ \\
\hline Streptococcus $(n=4)$ & $2.4-33.2$ & $>200$ & $3.8-49.9$ & $4.8-18.9$ & $32.4-45.7$ & $>200$ \\
\hline NCTC 10713 & 28.5 & $>200$ & $>200$ & 18.6 & $>200$ & $>200$ \\
\hline Achromobacter $(n=3)$ & $36.6->200^{*}$ & $>200$ & $>200$ & $50.6->200^{*}$ & $>200$ & $>200$ \\
\hline S. maltophilia $(n=3)$ & $3.3-34.6$ & $>200$ & $47.7->200^{*}$ & $9.6-29.4$ & $51.5->200^{*}$ & $>200$ \\
\hline
\end{tabular}

*only active against 1 isolate 
Table 2.

Mean log change in CFU/ml ( $\pm S D)$ at 3 hours to determine synergistic activity between LL37 and tobramycin.

\begin{tabular}{lllll}
\hline Genus & \multicolumn{4}{c}{ Log change in CFU/ml (mean \pm SD) } \\
& $\begin{array}{l}\text { LL37 } \\
(0.5 \mathrm{MIC})\end{array}$ & $\begin{array}{l}\text { Tobramycin } \\
(0.5 \mathrm{MIC})\end{array}$ & $\begin{array}{l}\text { LL37 }(0.5 \mathrm{MIC})+ \\
\text { tobramycin }(0.5 \\
\mathrm{MIC})\end{array}$ & Control \\
\hline $\begin{array}{l}\text { Pseudomonas } \\
(\mathbf{n}=5)\end{array}$ & $-0.31( \pm 0.22)$ & $-0.58( \pm 0.31)$ & $-0.92( \pm 0.37)$ & $0.02( \pm 0.02)$ \\
\hline $\begin{array}{l}\text { Staphylococcus } \\
(\mathbf{n}=5)\end{array}$ & $-1.37( \pm 0.26)$ & $-0.04( \pm 0.07)$ & $-3.82( \pm 1.05)$ & $0.01( \pm 0.01)$ \\
\hline $\begin{array}{l}\text { Streptococcus } \\
(\mathbf{n}=5)\end{array}$ & $-0.13( \pm 0.15)$ & $-1.12( \pm 1.51)$ & $-2.53( \pm 1.96)$ & $0.03( \pm 0.03)$ \\
\hline
\end{tabular}


Table 3

Mean log change in CFU/mL $( \pm S D)$ at 24 hours following challenge with ivacaftor or ciprofloxacin.

\section{Log change in CFU/mL (mean $\pm \mathrm{SD}$ )}

\begin{tabular}{llll}
\hline Genus & Ivacaftor & Ciprofloxacin & Control \\
& $(32 \mathrm{mg} / \mathrm{L})$ & $(5 \mathrm{mg} / \mathrm{L})$ & \\
\hline Pseudomonas $(\mathbf{n}=5)$ & $4.44( \pm 0.30)$ & $-5.83( \pm 0.28)$ & $3.84( \pm 0.79)$ \\
\hline Staphylococcus $(\mathbf{n}=5)$ & $-0.51( \pm 0.61)$ & $-2.06( \pm 4.33)$ & $3.37( \pm 0.44)$ \\
\hline Streptococcus $(\mathbf{n}=\mathbf{5})$ & $-3.16( \pm 2.25)$ & $-4.50( \pm 1.35)$ & $3.63( \pm 0.51)$ \\
\hline Achromobacter $(\mathbf{n}=\mathbf{3})$ & $2.83( \pm 0.27)$ & $-1.63( \pm 3.84)$ & $3.01( \pm 0.17)$ \\
\hline Stenotrophomonas $(\mathbf{n}=\mathbf{3})$ & $2.69( \pm 0.16)$ & $-5.83( \pm 0.29)$ & $3.11( \pm 0.01)$
\end{tabular}


Table 4

Mean log change in CFU/ml ( \pm SD) at 24 hours to determine synergistic activity between ivacaftor and tobramycin.

Log change in CFU/mL (mean \pm SD)

\begin{tabular}{|c|c|c|c|c|}
\hline Genus & $\begin{array}{l}\text { Ivacaftor } \\
\text { (32 mg/L) }\end{array}$ & $\begin{array}{l}\text { Tobramycin } \\
\text { (0.5 MIC) }\end{array}$ & $\begin{array}{l}\text { Ivacaftor (32 mg/L) \& } \\
\text { Tobramycin (0.5 MIC) }\end{array}$ & Control \\
\hline Pseudomonas $(n=5)$ & $3.91( \pm 1.57)$ & $3.69( \pm 0.66)$ & $2.46( \pm 1.61)$ & $3.84( \pm 0.49)$ \\
\hline Staphylococcus $(\mathrm{n}=5)$ & $0.13( \pm 0.45)$ & $3.53( \pm 0.15)$ & $-5.72( \pm 0.17)$ & $3.51( \pm 0.27)$ \\
\hline Streptococcus $(\mathrm{n}=5)$ & $-3.31( \pm 2.13)$ & $2.38( \pm 1.42)$ & $-5.53( \pm 0.61)$ & $3.49( \pm 0.59)$ \\
\hline
\end{tabular}


Fig. 1. Time-kill curves for A) P. aeruginosa $(n=5)$, B) $S$. aureus $(n=5)$ and C) Streptococcus spp. $(\mathrm{n}=5)$ challenged with ivacaftor at a range of concentrations (1-32 $\mathrm{mg} / \mathrm{L})$ plotted as the mean change in CFU/ml $( \pm S D)$.

Fig. 2. Activity of ivacaftor and tobramycin $(0.5 \mathrm{MIC})$ in combination against $A) P$. aeruginosa $(n=5), B)$ S. aureus $(n=5)$ and C) Streptococcus spp. $(n=5)$; the mean change in $\mathrm{CFU} / \mathrm{ml}( \pm \mathrm{SD})$ for each genera is shown.

Fig. 3. Effect of ivacaftor (32mg/L) and ciprofloxacin ( $5 \mathrm{mg} / \mathrm{L})$ on biofilm formation by P. aeruginosa $(n=3), S$. aureus $(n=5)$, Streptococcus spp. $(n=4)$, Achromobacter spp. $(n=2)$ and Stenotrophomonas spp. $(n=3)$. Adherence is plotted as the mean of 8 replicates $( \pm S D)$. Non-adherent bacteria were not included in the analysis. $P \leq 0.01^{* *}$, $\mathrm{P} \leq 0.001^{* * *}$

Fig. 4. Effect of ivacaftor in comparison to tobramycin on intraperitoneal infection using P. aeruginosa (PAO1) in C57bl6 albino mice. A) total number of cells recovered from the peritoneal lavage, B) cell viability, C) Total viable count (TVC) of $P$. aeruginosa recovered from the peritoneal lavage, D) IL-6; E) KC. Results are plotted as the mean value from 5 mice $( \pm S D) . P \leq 0.05^{*}, P \leq 0.01^{* *}, P \leq 0.001^{* * *}$. 
Fig. 1.
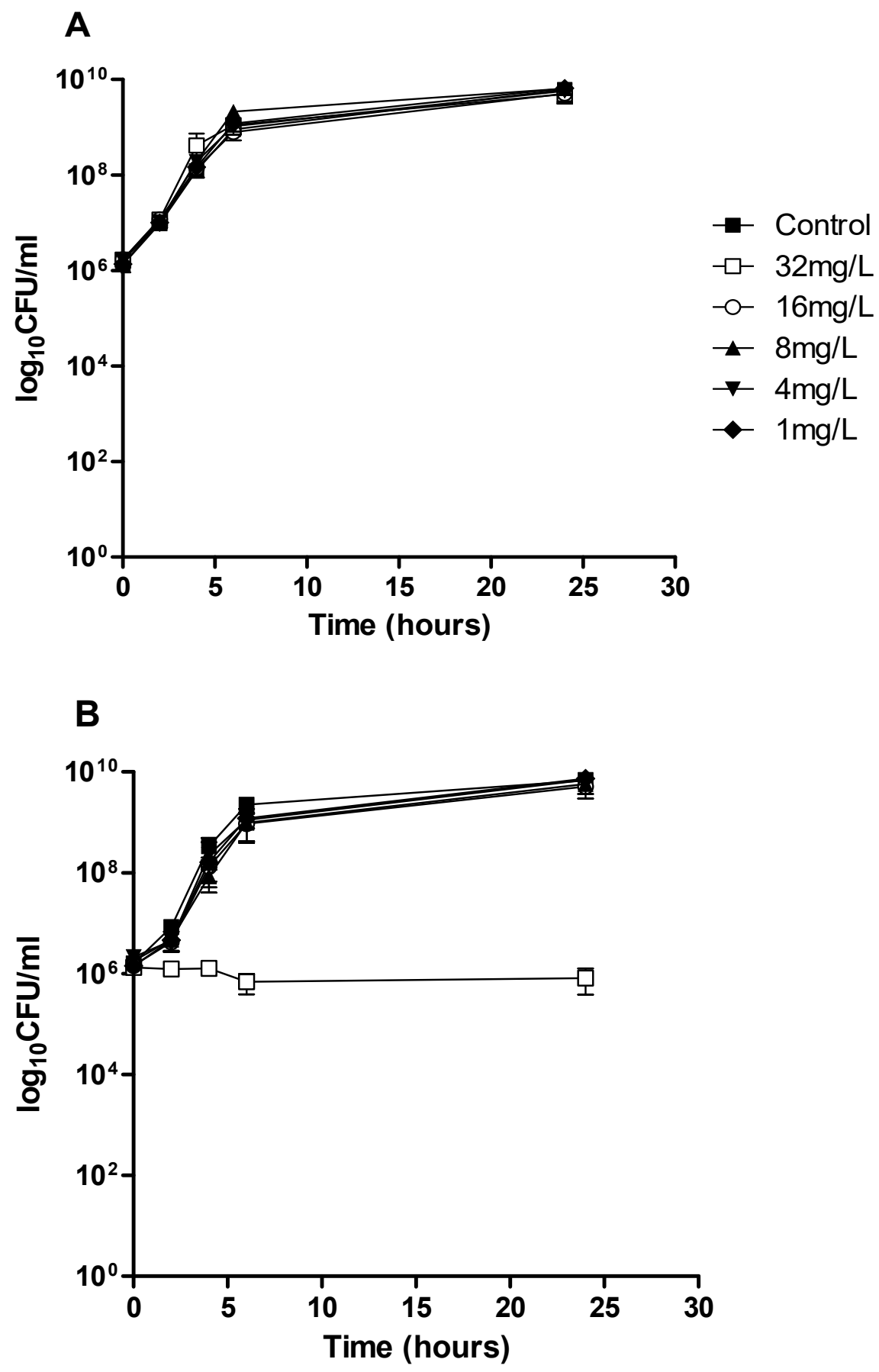


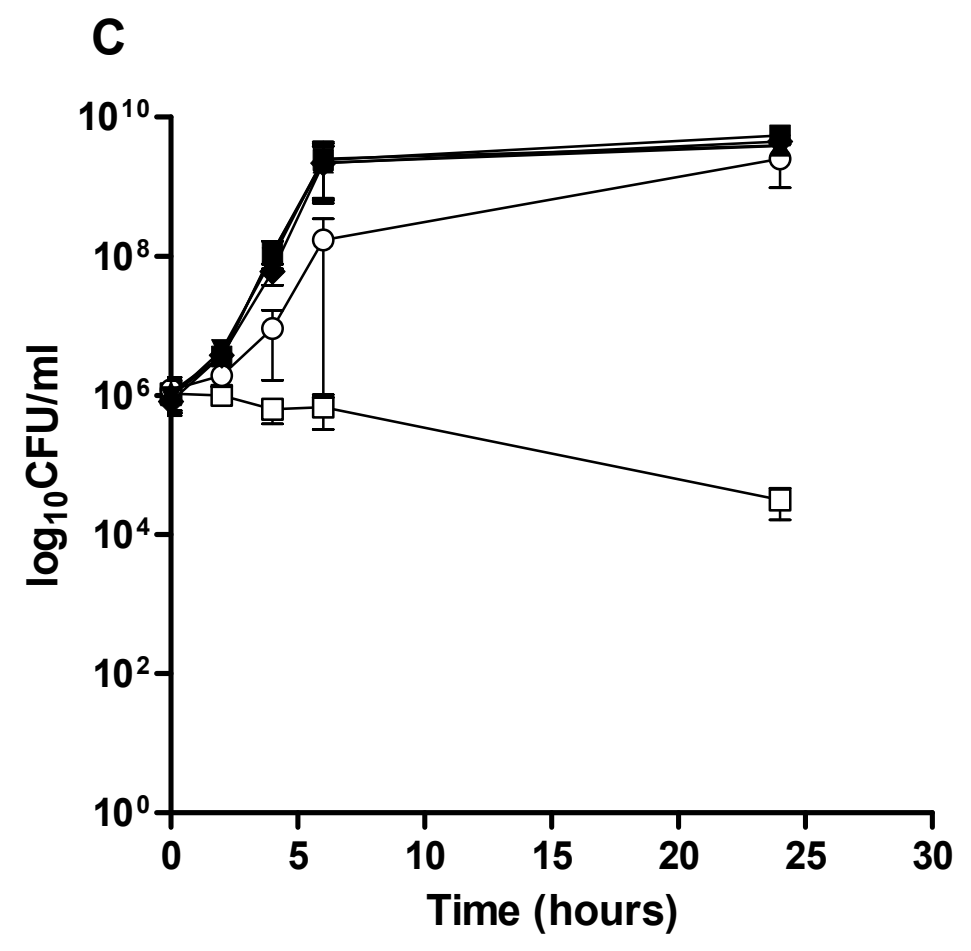


Fig. 2.

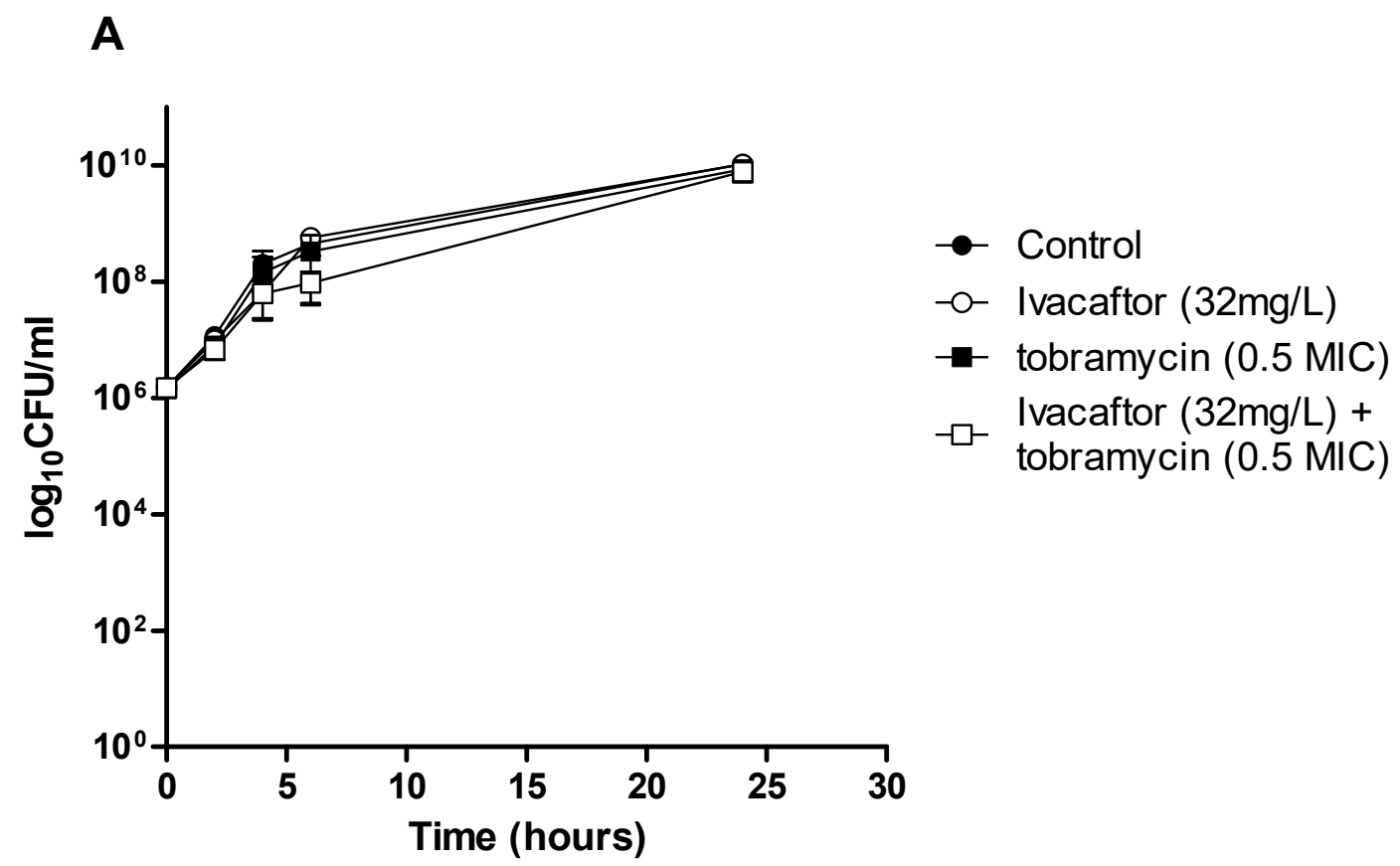

\section{B}

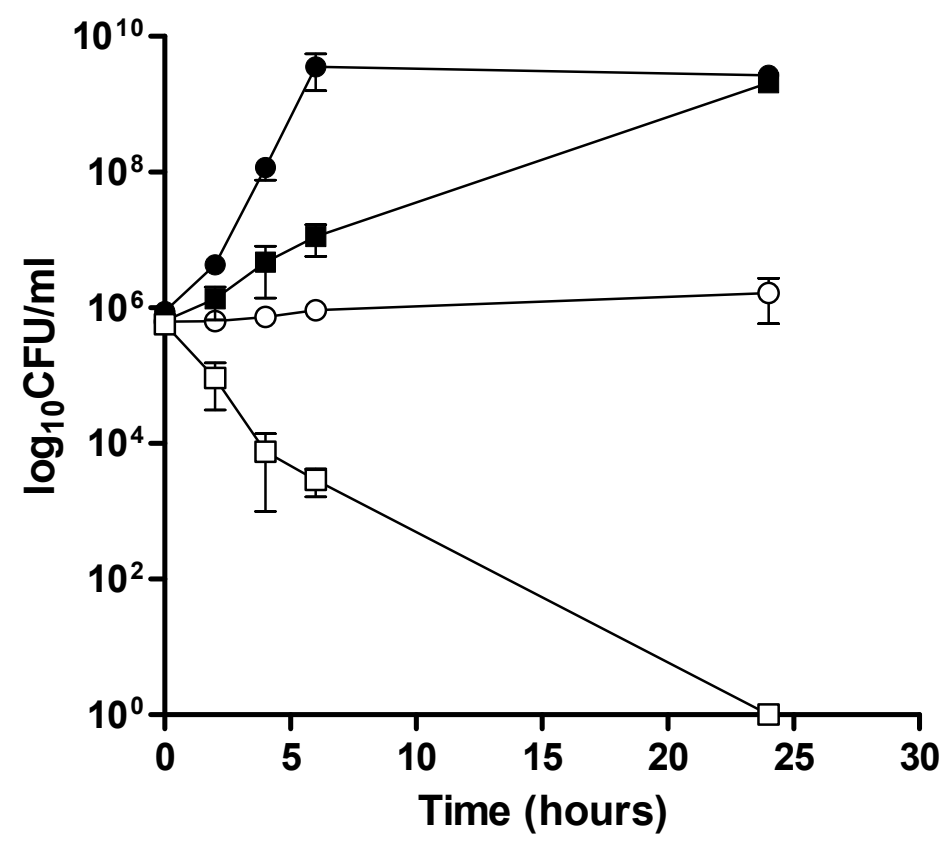




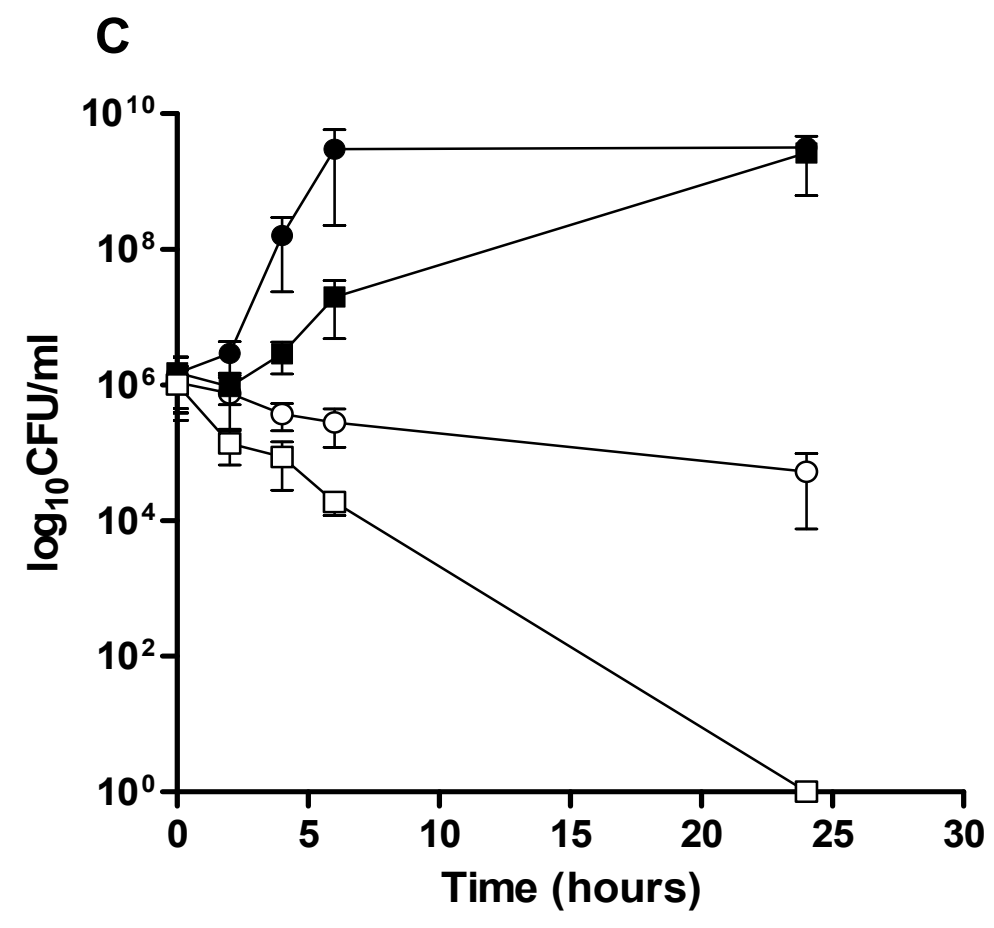


Fig. 3.

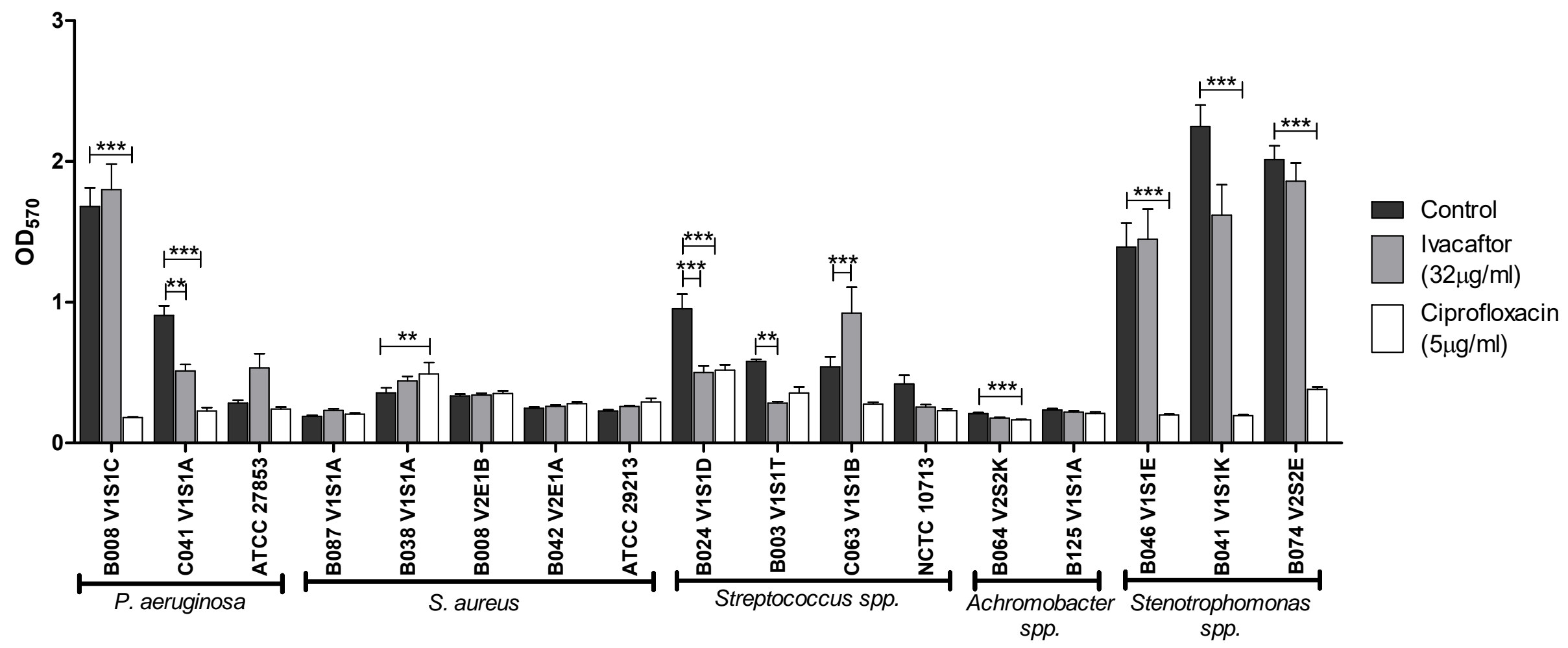


Fig. 4.

A

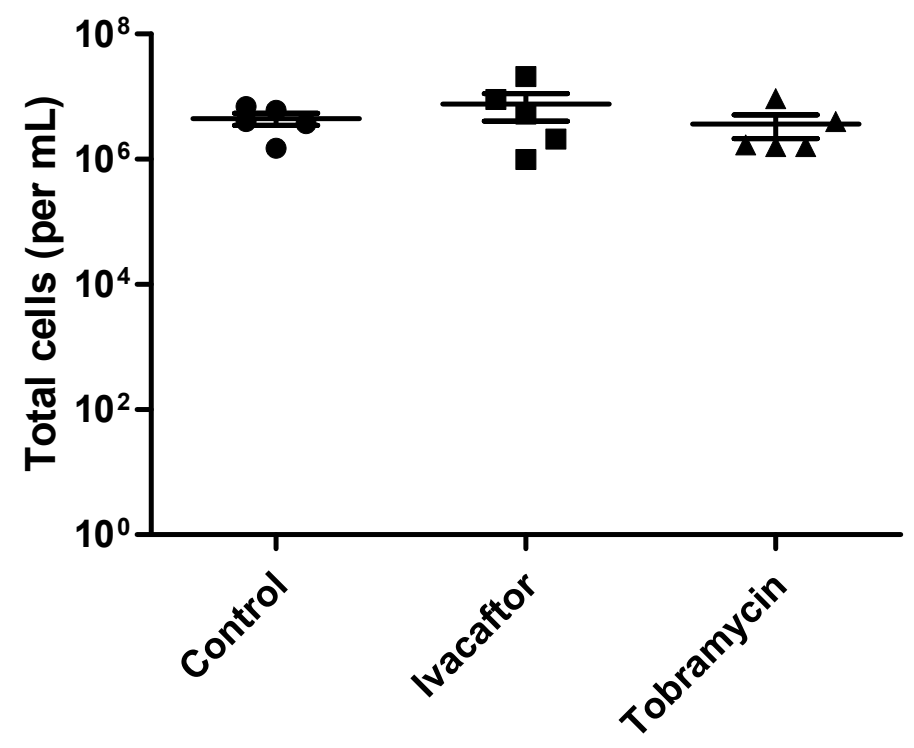

B

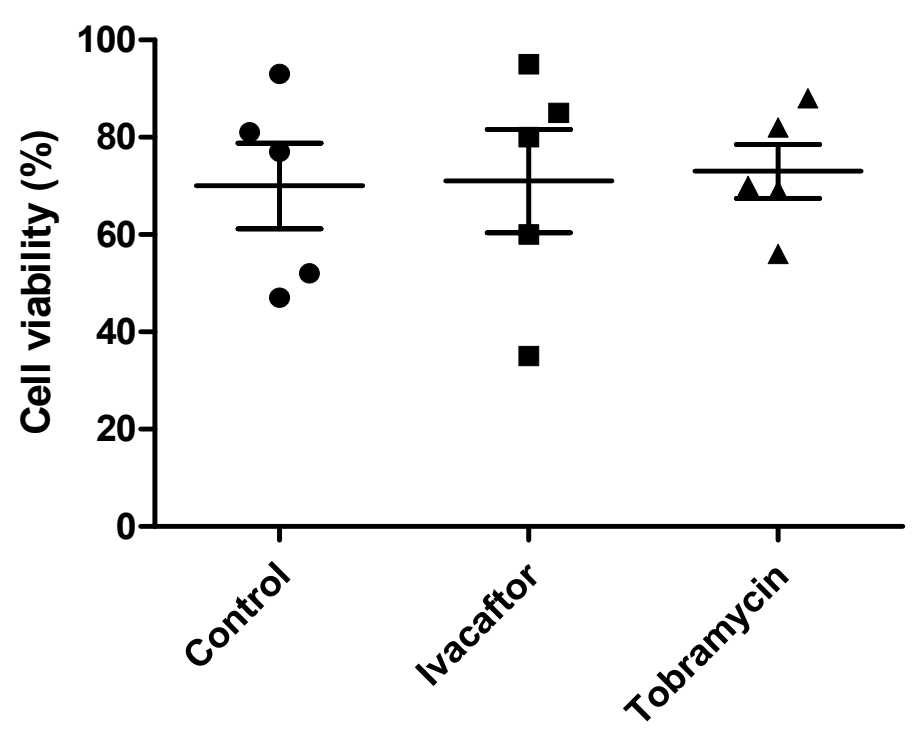


C
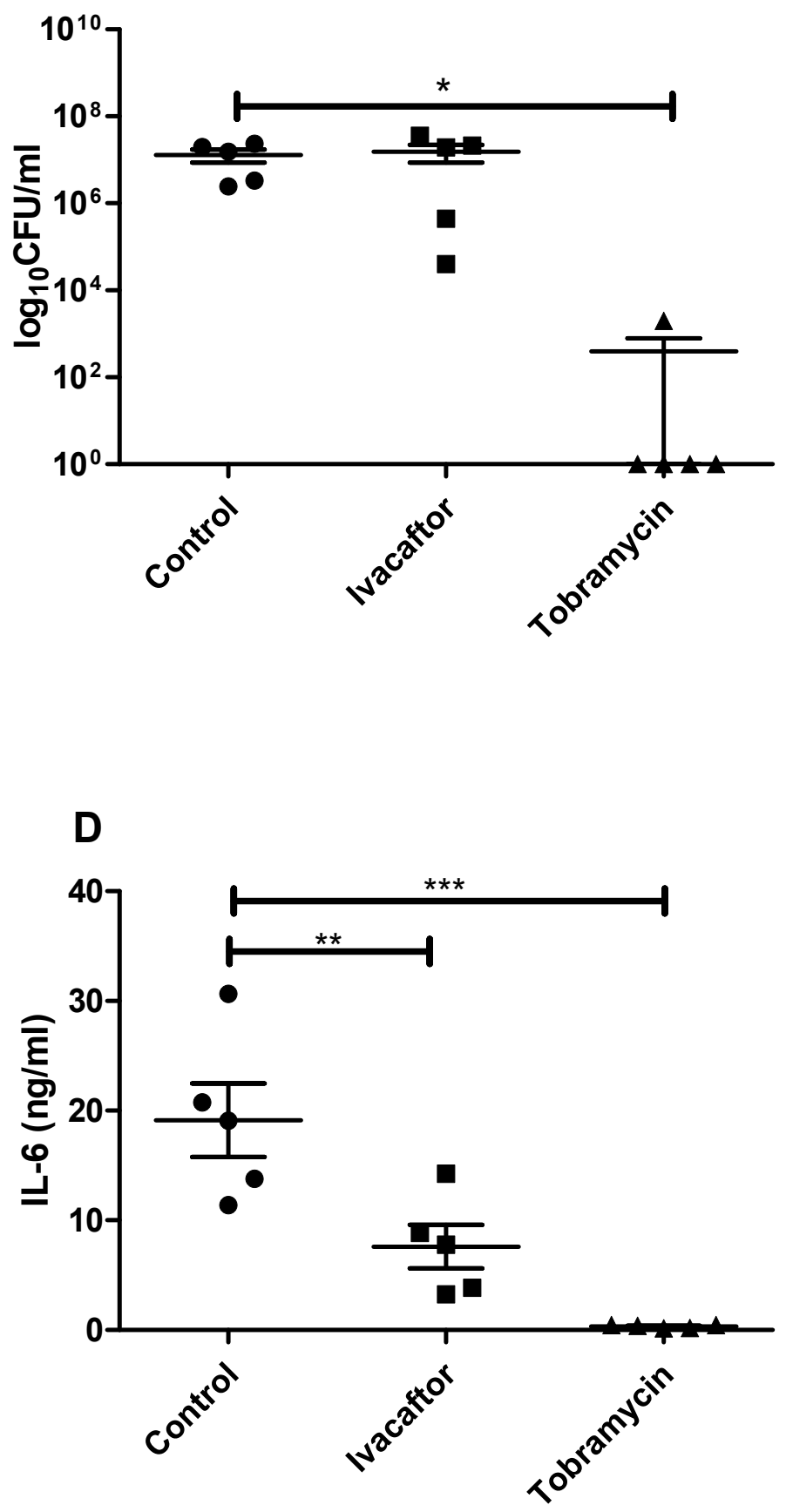


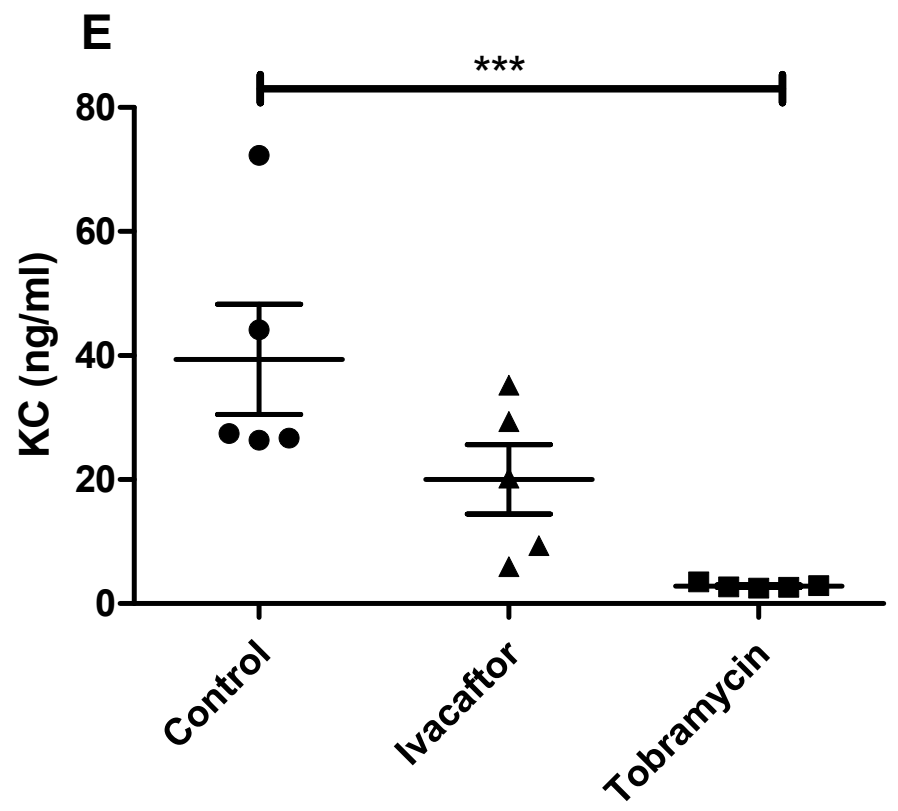

40 
Supplementary Table 1. MIC (mg/L) of a panel of antibiotics against the isolates tested. Breakpoints, where available, are taken from the EUCAST guidelines [39].

\begin{tabular}{|c|c|c|c|c|c|c|c|c|c|c|c|}
\hline & Amoxicillin & Azithromycin & Ceftazidime & $\begin{array}{c}\text { Chloramph } \\
\text { enicol }\end{array}$ & Ciprofloxacin & Clindamycin & $\begin{array}{c}\text { Co- } \\
\text { amoxiclav }\end{array}$ & Colistin & Doxycycline & Meropenem & Tobramycin \\
\hline \multicolumn{12}{|l|}{ P. aeruginosa } \\
\hline $\mathrm{B} 004 \mathrm{~V} 2 \mathrm{~S} 2 \mathrm{~B}$ & $>256$ & $>256$ & $>256$ & 12 & 2 & $>256$ & 48 & 3 & 24 & 12 & 6 \\
\hline B008 V1S1C & 3 & 48 & 1.5 & 16 & 3 & $>256$ & 3 & 1 & $>256$ & 0.094 & 1.5 \\
\hline C041 V1S1A & $>256$ & 48 & 1 & $>256$ & 0.125 & $>256$ & $>256$ & 1.5 & $>256$ & 0.38 & 0.75 \\
\hline C070 V1S1A & $>256$ & 128 & 1 & $>256$ & 0.5 & $>256$ & 256 & 1 & $>256$ & 0.094 & 1 \\
\hline ATCC 27853 & $>128$ & 32 & 1 & $>256$ & 0.25 & $>256$ & 128 & 4 & 48 & 0.25 & 0.5 \\
\hline Breakpoints & & & $R>8$ & & $S \leq 0.5, R>1$ & & & $R>4$ & & $S \leq 2, R>8$ & $R>4$ \\
\hline \multicolumn{12}{|l|}{ S. aureus } \\
\hline B038 V1S1A & 24 & $>256$ & 64 & 3 & 0.38 & 0.047 & 12 & $>256$ & 4 & 0.5 & 32 \\
\hline B087 V1S1A & 1.5 & $>256$ & 16 & 3 & 0.19 & 0.25 & 8 & $>256$ & 0.094 & 0.38 & 0.38 \\
\hline BO42 V2E1A & 24 & $>256$ & $>256$ & 2 & $>32$ & 8 & 48 & 96 & 0.094 & $>32$ & 0.75 \\
\hline B008 V2E1B & 8 & $>256$ & 256 & 2 & $>32$ & 0.047 & 12 & 32 & 0.064 & 1 & 0.094 \\
\hline ATCC 29213 & 0.5 & 0.12 & 8 & 2 & 0.5 & 0.06 & 0.25 & $>256$ & 0.19 & 0.06 & 0.5 \\
\hline Breakpoints & & $S \leq 1, R>2$ & & $R>8$ & $R>1$ & $\begin{array}{c}S \leq 0.25 \\
R>0.5\end{array}$ & & & $S \leq 1, R>2$ & & $R>1$ \\
\hline \multicolumn{12}{|l|}{ Streptococcus sp. } \\
\hline B012 V1S1Q (S. anginosus) & 0.064 & 0.38 & 3 & 2 & 1.5 & 0.094 & 0.094 & $>256$ & 3 & 0.064 & 96 \\
\hline B024 V1S1D (S. mitis) & 0.032 & 6 & 1 & 1.5 & 4 & 0.094 & 0.047 & $>256$ & 1.5 & 0.064 & 96 \\
\hline B003 V1S1T (S. constellatus) & 0.5 & $>256$ & 4 & 2 & 1 & 0.125 & 0.25 & 64 & 12 & 0.094 & 0.125 \\
\hline C063 V1S1B (S. constellatus) & 0.094 & 0.19 & 2 & 1.5 & 1.5 & 0.094 & 0.094 & $>256$ & 1.5 & 0.094 & 3 \\
\hline NCTC 10713 (S. anginosus) & 0.19 & 0.25 & 3 & 2 & 1 & 0.064 & 0.38 & $>256$ & 1 & 0.064 & 192 \\
\hline Breakpoints & $S \leq 0.5, R>2$ & $\begin{array}{l}\mathrm{S} \leq 0.25 \\
\mathrm{R}>0.5^{*}\end{array}$ & & $\mathrm{R}>8^{*}$ & $\begin{array}{l}\mathrm{S} \leq 0.25 \\
\mathrm{R}>0.5^{*}\end{array}$ & $R>0.5$ & & & $\mathrm{~S} \leq 1, \mathrm{R}>\mathbf{2}^{*}$ & $R>2$ & \\
\hline \multicolumn{12}{|l|}{ Achromobacter sp. } \\
\hline BO64 V2S2K (A. insolitus) & 4 & 32 & 2 & 2 & 1.5 & $>256$ & 8 & 0.38 & 1.5 & 0.38 & 12 \\
\hline B125 V1S1A (A. insolitus) & $>256$ & $>256$ & $>256$ & 3 & $>32$ & $>256$ & $>256$ & 0.25 & 198 & $>32$ & $>1024$ \\
\hline BO32 V2E1D (A. spanius) & & $>256$ & 16 & 6 & $>32$ & $>256$ & 3 & $>256$ & 16 & & $>1024$ \\
\hline Breakpoints & \multicolumn{2}{|c|}{ No breakpoints available } & & & & & & & & & \\
\hline \multicolumn{12}{|l|}{ S. maltophilia } \\
\hline BO46 V1S1E & 4 & $>256$ & 0.75 & 2 & 4 & $>256$ & 1.5 & 32 & 1.5 & 2 & 1.5 \\
\hline BO74 V2S2E & $>256$ & 32 & 32 & 3 & 2 & $>256$ & $>256$ & 4 & 3 & $>32$ & 48 \\
\hline B041 V1S1K & & $>256$ & 96 & 8 & $>32$ & $>256$ & 64 & 0.38 & 48 & $>32$ & 96 \\
\hline Breakpoints & \multicolumn{2}{|c|}{ No breakpoints available } & & & & & & & & & \\
\hline
\end{tabular}

"MRSA; *Indicates breakpoints for S. pneumoniae as no breakpoints available for S. viridans group 
Supplementary Table 2. MIC (mg/L) of antimicrobial peptides against CF respiratory isolates

\begin{tabular}{|c|c|c|c|c|c|c|}
\hline Isolate & LL37 & HßD1 & HßD2 & HßD3 & HßD4 & SLPI \\
\hline \multicolumn{7}{|l|}{ P. aeruginosa } \\
\hline B004 V2S2B & 22.8 & $\geq 200$ & $\geq 200$ & 8.1 & 49.3 & $\geq 200$ \\
\hline B008 V1S1C & 3.9 & $\geq 200$ & 43.4 & 6.4 & 46.6 & $\geq 200$ \\
\hline C041 V1S1A & 9.5 & $\geq 200$ & 51.3 & 9.6 & 44.1 & $\geq 200$ \\
\hline C070 V1S1A & 9.7 & $\geq 200$ & 47.7 & 17.6 & 39.1 & $\geq 200$ \\
\hline ATCC 27853 & 3.2 & $\geq 200$ & 28.6 & 13.9 & 17.8 & $\geq 200$ \\
\hline \multicolumn{7}{|l|}{ S. aureus } \\
\hline BO38 V1S1A & 29.9 & $\geq 200$ & $\geq 200$ & 9.2 & $\geq 200$ & $\geq 200$ \\
\hline B087 V1S1A & 17.8 & $\geq 200$ & $\geq 200$ & 8.9 & $\geq 200$ & $\geq 200$ \\
\hline BO42 V2E1A & 22.4 & $\geq 200$ & $\geq 200$ & 9.4 & $\geq 200$ & $\geq 200$ \\
\hline B008 V2E1B & 15.7 & $\geq 200$ & $\geq 200$ & 9.6 & $\geq 200$ & $\geq 200$ \\
\hline ATCC 29213 & 21.5 & $\geq 200$ & $\geq 200$ & 12.7 & $\geq 200$ & $\geq 200$ \\
\hline \multicolumn{7}{|l|}{ Streptococcus spp. } \\
\hline B012 V1S1Q (S. anginosus) & 2.4 & $\geq 200$ & 49.9 & 8.9 & 45.7 & $\geq 200$ \\
\hline B024 V1S1D (S. mitis) & 33.2 & $\geq 200$ & 42.9 & 13.9 & 32.4 & $\geq 200$ \\
\hline B003 V1S1T (S. constellatus) & 6.5 & $\geq 200$ & 3.8 & 4.8 & 38.5 & $\geq 200$ \\
\hline C063 V1S1B (S. constellatus) & 29.0 & $\geq 200$ & 43.0 & 18.9 & 36.0 & $\geq 200$ \\
\hline NCTC 10713 (S. anginosus) & 28.5 & $\geq 200$ & $\geq 200$ & 18.6 & $\geq 200$ & $\geq 200$ \\
\hline \multicolumn{7}{|l|}{ Achromobacter sp. } \\
\hline BO64 V2S2K (A. insolitus) & 36.6 & $\geq 200$ & $\geq 200$ & 50.6 & $\geq 200$ & $\geq 200$ \\
\hline B125 V1S1A (A. insolitus) & $\geq 200$ & $\geq 200$ & $\geq 200$ & $\geq 200$ & $\geq 200$ & $\geq 200$ \\
\hline BO32 V2E1D (A. spanius) & $\geq 200$ & $\geq 200$ & $\geq 200$ & $\geq 200$ & $\geq 200$ & $\geq 200$ \\
\hline \multicolumn{7}{|l|}{ S. maltophilia } \\
\hline B046 V1S1E & 3.3 & $\geq 200$ & $\geq 200$ & 23.6 & $\geq 200$ & $\geq 200$ \\
\hline BO74 V2S2E & 34.6 & $\geq 200$ & $\geq 200$ & 29.4 & $\geq 200$ & $\geq 200$ \\
\hline BO41 V1S1K & 18.6 & $\geq 200$ & 47.7 & 9.6 & 51.5 & $\geq 200$ \\
\hline
\end{tabular}


Supplementary Table 3. Synergy between LL37 and tobramycin against CF respiratory isolates (change in log CFU/ml) at 3 hours.

\begin{tabular}{|c|c|c|c|c|}
\hline & \multicolumn{4}{|c|}{ Log change in CFU/ml (士SD) } \\
\hline & Control & $\begin{array}{l}\text { LL37 }(0.5 \mathrm{MIC})+ \\
\text { tobramycin }(0.5 \mathrm{MIC})\end{array}$ & $\begin{array}{l}\text { LL37 } \\
(0.5 \mathrm{MIC})\end{array}$ & $\begin{array}{l}\text { Tobramycin } \\
(0.5 \mathrm{MIC})\end{array}$ \\
\hline \multicolumn{5}{|l|}{ P. aeruginosa } \\
\hline B004 V2S2B & 0.02 & -1.17 & -0.17 & -0.90 \\
\hline B008 V1S1C & 0.00 & -0.70 & -0.55 & -0.46 \\
\hline C041 V1S1A & 0.01 & -1.52 & 0.05 & -0.96 \\
\hline C070 V1S1A & 0.07 & -0.58 & -0.41 & -0.40 \\
\hline ATCC 27853 & 0.01 & -0.62 & -0.48 & -0.16 \\
\hline Mean & $0.02( \pm 0.02)$ & $-0.92( \pm 0.37)$ & $-0.31( \pm 0.22)$ & $-0.58( \pm 0.31)$ \\
\hline \multicolumn{5}{|l|}{ S. aureus } \\
\hline BO38 V1S1A & 0.01 & -1.72 & -0.91 & -0.15 \\
\hline B087 V1S1A & 0.02 & $-4.30^{*}$ & -1.61 & 0.02 \\
\hline BO42 V2E1A & 0.02 & $-4.48^{*}$ & -1.64 & 0.03 \\
\hline BO08 V2E1B & 0.01 & $-4.30^{*}$ & -1.40 & 0.00 \\
\hline ATCC 29213 & 0.00 & $-4.30^{*}$ & -1.30 & -0.08 \\
\hline Mean & $0.01( \pm 0.01)$ & $-3.82( \pm 1.05)$ & $-1.37( \pm 0.26)$ & $-0.04( \pm 0.07)$ \\
\hline \multicolumn{5}{|l|}{ Streptococcus spp. } \\
\hline B012 V1S1Q (S. anginosus) & 0.01 & $-4.18^{*}$ & -0.10 & -0.17 \\
\hline B024 V1S1D (S. mitis) & 0.02 & $-4.05^{*}$ & -0.26 & -4.05 \\
\hline B003 V1S1T (S. constellatus) & 0.08 & 0.21 & 0.14 & 0.03 \\
\hline C063 V1S1B (S. constellatus) & 0.01 & -0.49 & -0.18 & -0.38 \\
\hline NCTC 10713 (S. anginosus) & 0.01 & $-4.14^{*}$ & -0.24 & -1.01 \\
\hline Mean & $0.03( \pm 0.03)$ & $-2.53( \pm 1.96)$ & $-0.13( \pm 0.15)$ & $-1.12( \pm 1.51)$ \\
\hline
\end{tabular}

*Synergy (defined as $a \geq 2 \log _{10}$ decrease in total viable count (TVC) compared to the starting inoculum and as a $\geq 2$ log 10 decrease in TVC by the combination compared to the most active single agent) 
Supplementary Figure 1. Antimicrobial activity of ivacaftor at a range of concentrations against $P$. aeruginosa isolates; A) B004 V2S2B, B) B008 V1S1C, C) C041 V1S1A, D) C070 V1S1A and E) ATCC 27853.
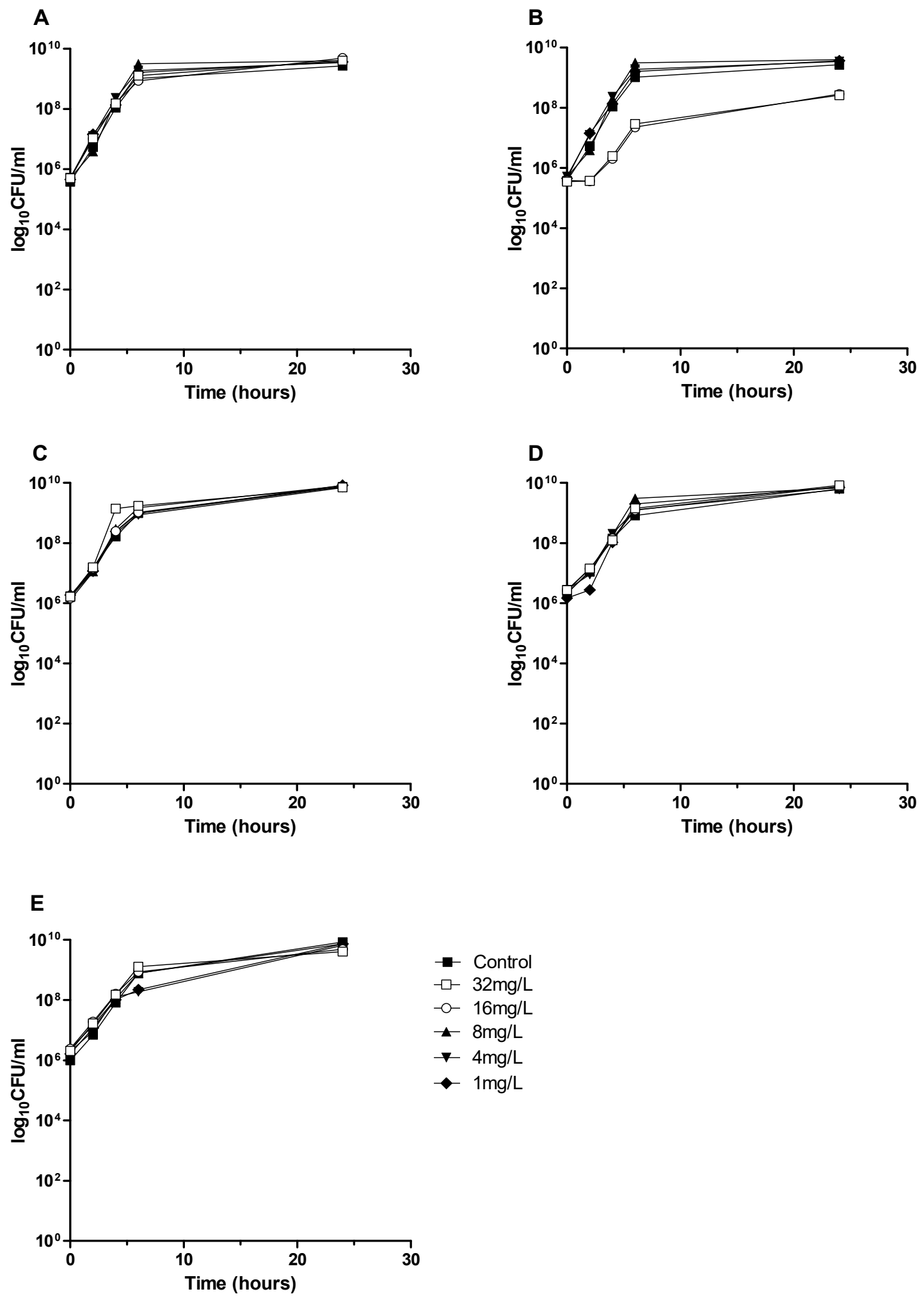
Supplementary Figure 2. Antimicrobial activity of ivacaftor at a range of concentrations against S. aureus isolates; A) B038 V1S1A, B) B042 V2E1A, C) B087 V1S1A, D) B008 V2E1B and E) ATCC 29213.
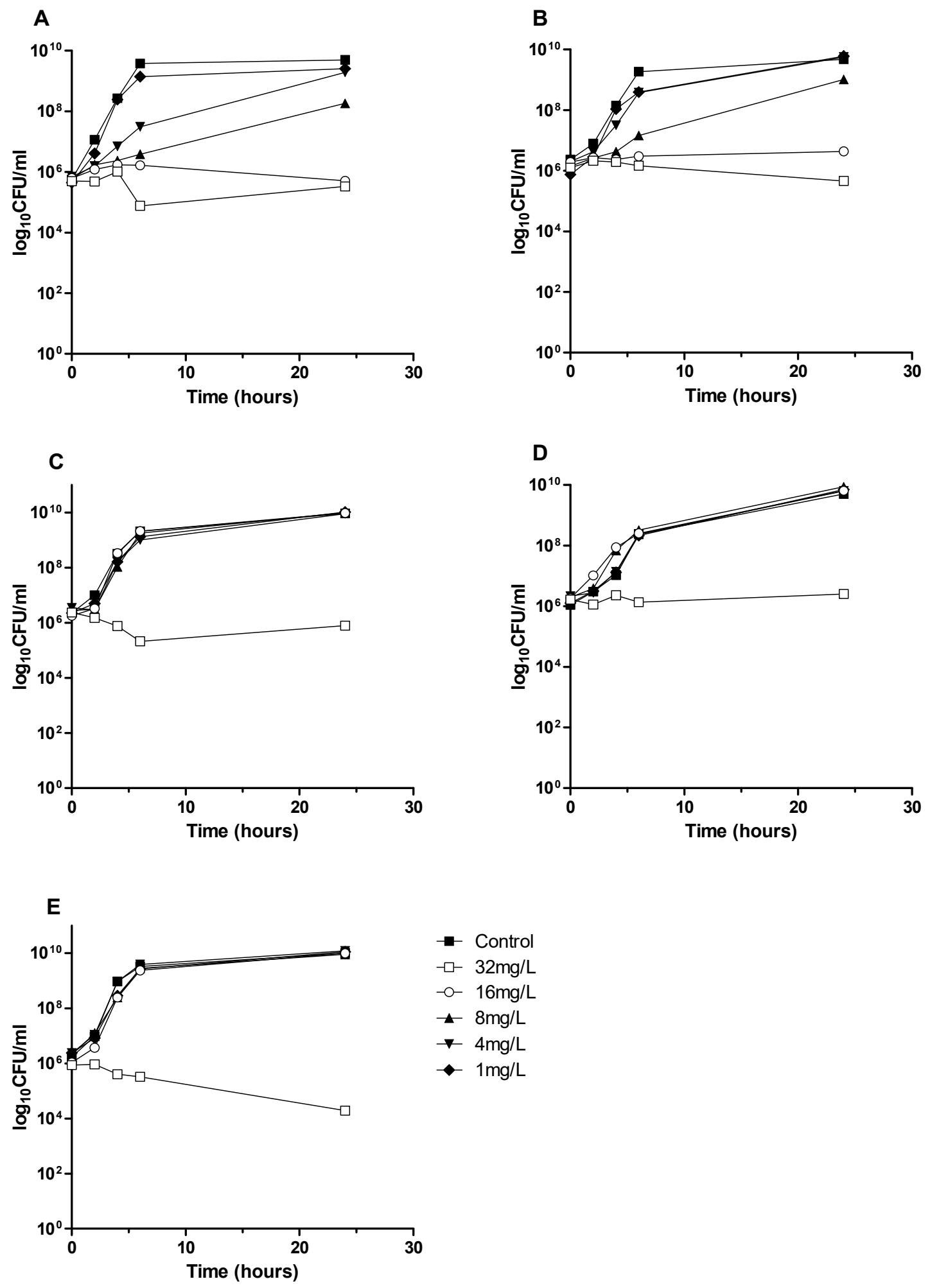
Supplementary Figure 3. Antimicrobial activity of ivacaftor at a range of concentrations against Streptococcus spp. isolates; A) B012 V1S1Q (S. anginosus), B) C063 V1S1B (S. constellatus), C) B003 V1S1T (S. constellatus), D) B024 V1S1D (S. mitis), E) NCTC 10713 (S. anginosus).
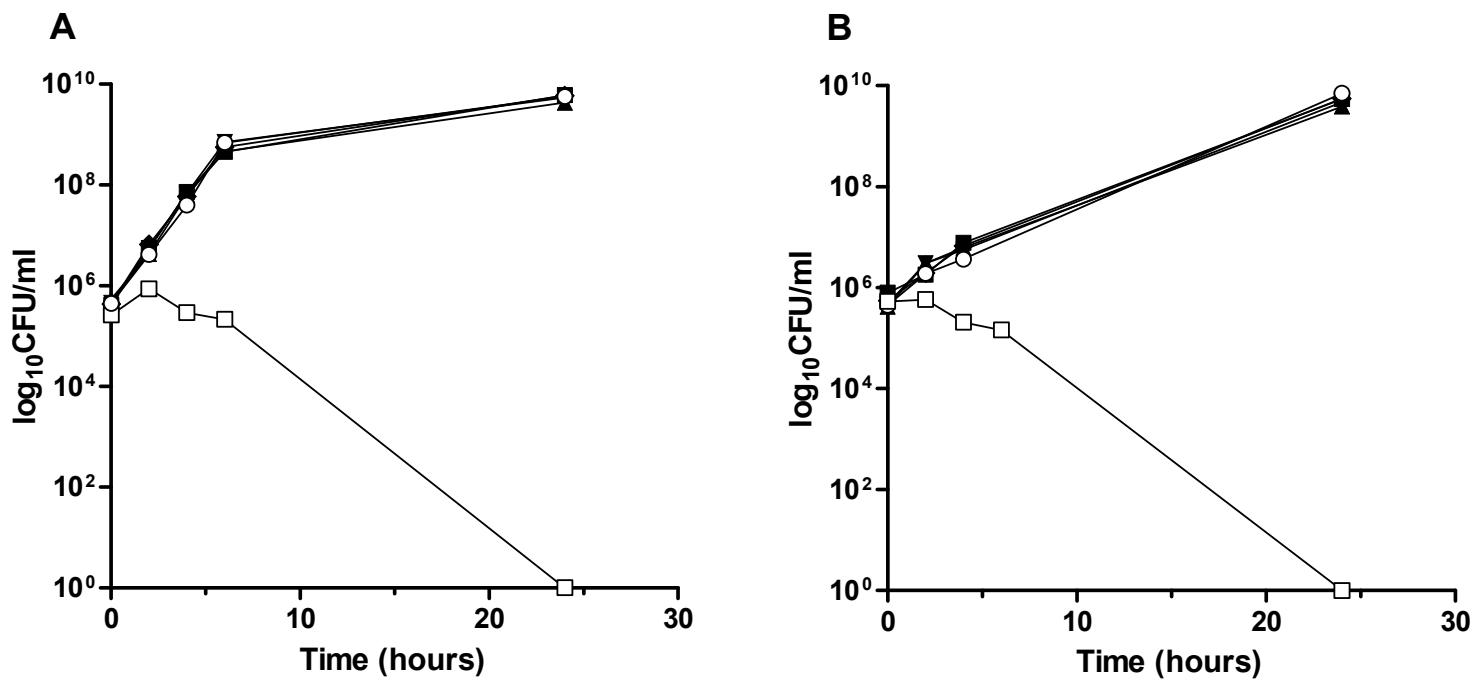

\section{C}
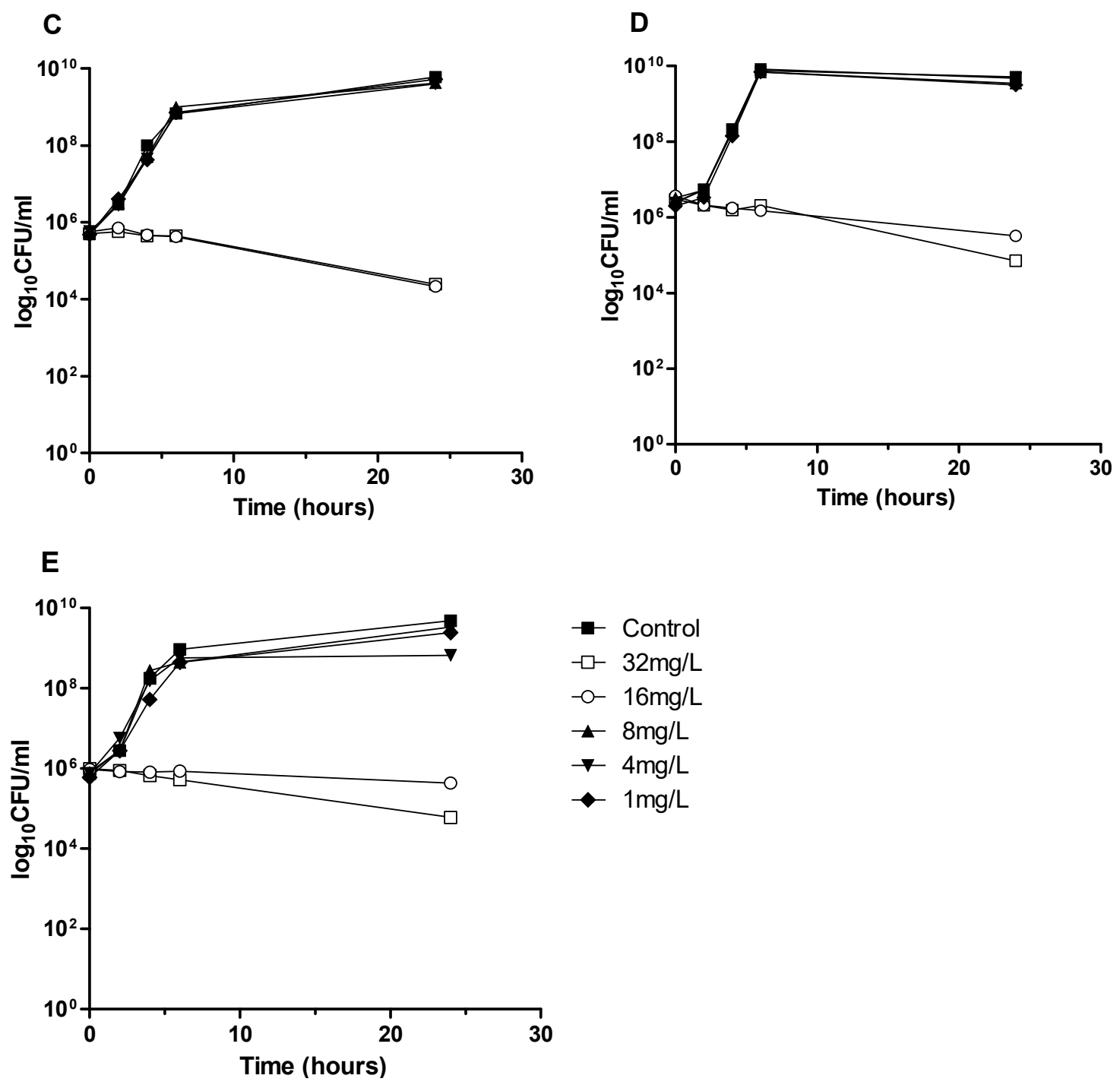